\title{
Recent Progress in Pressure Sensors for Wearable Electronics: From Design to Applications
}

\author{
Yeongjun Kim(1) and Je Hoon Oh * \\ Department of Mechanical Engineering, Hanyang University, 55 Hanyangdeahak-ro, Sangnok-gu, Ansan, \\ Gyeonggi-do 15588, Korea; dudwns6215@hanyang.ac.kr \\ * Correspondence: jehoon@hanyang.ac.kr; Tel.: +82-31-400-5252
}

Received: 17 August 2020; Accepted: 10 September 2020; Published: 14 September 2020

\begin{abstract}
In recent years, innovative research has been widely conducted on flexible devices for wearable electronics applications. Many examples of wearable electronics, such as smartwatches and glasses, are already available to consumers. However, strictly speaking, the sensors used in these devices are not flexible. Many studies are underway to address a wider range of wearable electronics and the development of related fields is progressing very rapidly. In particular, there is intense interest in the research field of flexible pressure sensors because they can collect and use information regarding a wide variety of sources. Through the combination of novel materials and fabrication methods, human-machine interfaces, biomedical sensors, and motion detection techniques, it is now possible to produce sensors with a superior level of performance to meet the demands of wearable electronics. In addition, more compact and human-friendly sensors have been invented in recent years, as biodegradable and self-powered sensor systems have been studied. In this review, a comprehensive description of flexible pressure sensors will be covered, and design strategies that meet the needs for applications in wearable electronics will be presented. Moreover, we will cover several fabrication methods to implement these technologies and the corresponding real-world applications.
\end{abstract}

Keywords: flexible pressure sensors; wearable electronics; porous structures; surface modification; composite material

\section{Introduction}

Modern society strives to make the world smart and comfortable. Numerous electronic devices have been actively researched and developed to realize these goals. Through a number of well-developed devices, flexible and wearable devices that change the way we work and play are on the horizon. Electronic devices, such as smartphones and smartwatches, enable an unprecedented amount of information to be easily accessed. Many researchers are immersed in the continuing effort to make lighter and more compact devices and systems. In particular, many studies have been conducted to realize a compact system capable of providing interaction between a human and machine. For human-machine interaction, the role of the sensor is important, and in particular, pressure sensors can acquire substantial information from people, so most research is being conducted on the human/sensor interface.

Pressure sensors can measure various information sources acting on the inside and outside of human skin, as well as on the surface of an object or a machine [1-8]. However, there are many difficulties in applying conventional pressure sensors to wearable electronics because they are traditionally made of stiff materials. Therefore, in order to apply pressure sensors to wearable electronics, such as human-machine interfaces, biomedical sensors, and motion detection, it is important to develop a flexible sensor that is capable of sensitive and consistent performance, even on a curved surface. Thus, the flexibility of the electrode, as well as the sensing layer, should be secured, and various electrical 
performances, including the sensitivity, detection limit, response time, and mechanical durability must be guaranteed.

Many studies are underway to produce flexible pressure sensors. In particular, there are two main aspects to realize flexible pressure sensors; one is to use inherently flexible materials, and the second is to produce flexibility by forming specially designed structures. Flexible pressure sensors using functional polymers, such as silicone rubber, have received substantial attention. Silicone rubber, like polydimethylsiloxane (PDMS), has excellent flexibility and is particularly suitable for wearable electronics due to its biocompatible nature [9-11]. Recently, composite materials have been made by mixing $\mathrm{BaTiO}_{3}$, carbon nanotubes (CNTs), reduced graphene oxide (rGO), carbon black (CB), $\mathrm{Ag}$ nanowires (Ag NWs), and Ag nanoparticles (Ag NPs) to improve the electrical performance of silicone rubber [12-17]. These composite materials show electrical properties superior to bulk materials, which can significantly improve the electrical performance of the sensors.

The fabrication of the sensing layer to have a porous structure, or manufacturing it in NW form, is another major way to give the sensor flexibility [18-22]. The nano-size or micro-size structural form of materials can provide excellent flexibility, even if the materials are naturally brittle. In particular, if a naturally flexible material is produced to have various structures, the flexibility can be significantly modified. A flexible material and specially structured sensing layer not only provide excellent mechanical durability, but also improve electrical performances [23-27].

In addition to flexible sensors, self-powered sensor systems have recently been actively studied [28-35]. These self-powered sensor systems do not require an additional power source such as a battery, so they show promise for application in wearable electronics. In particular, triboelectric nanogenerators (TENGs), which were first invented by Wang's group in 2012 [36], have opened up a new field in self-powered sensor systems, in addition to piezoelectric pressure sensors. TENGs are electronic devices that combine electrostatic induction and the triboelectric effect, and they produce a relatively high voltage output from the contact/separation of two friction layers. In addition, biodegradable sensors became a new active research field in wearable electronics [37]. Biodegradable sensors are particularly popular in the biomedical field and have environmentally positive effects.

In this review, we focus on providing an introduction to fundamental designs based on the type of pressure sensor. In the next section, we present fabrication methods and design strategies for flexible pressure sensors. In Section 4, the applications of flexible pressure sensors are briefly introduced with several examples. Finally, we summarize the recent progress in flexible pressure sensors, offering perspectives regarding the future.

\section{Pressure Transduction Mechanism and Design Principles}

Pressure sensors are categorized into resistive, capacitive, and piezoelectric types, based on the pressure transduction mechanism (Figure 1). Numerous studies have been conducted to improve electrical performances, such as the sensitivity, detection limit, cyclic stability, and so forth. Studies of the active layer's materials, structure design, and fabrication methods have been actively conducted. In this section, we mainly focus on the sensing mechanism and design strategies according to the type of sensor. 
(a)
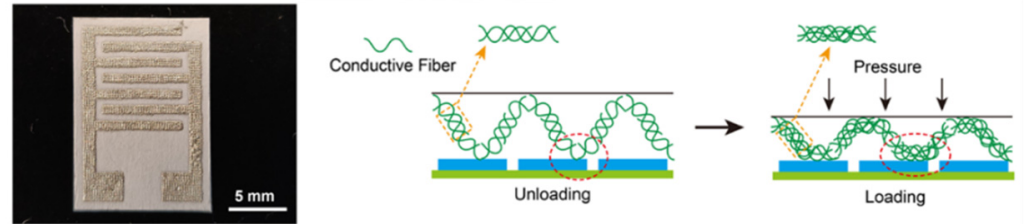

(b)
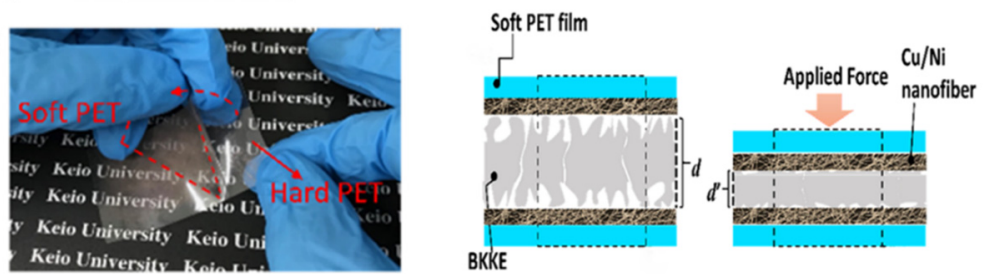

(c)
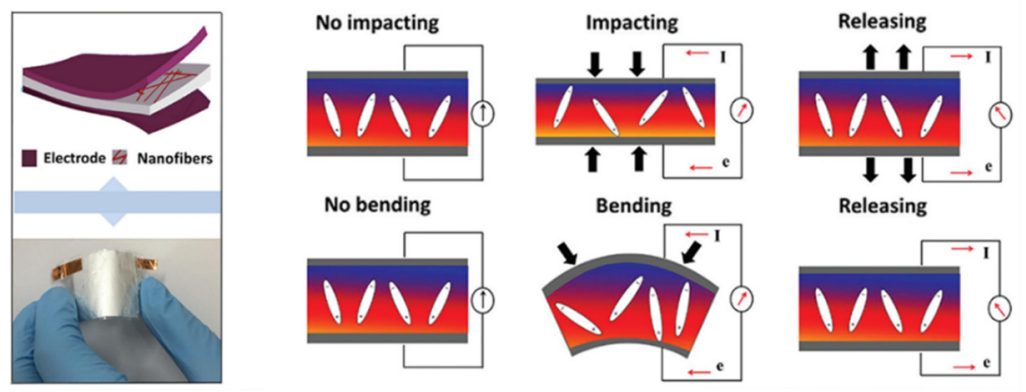

Figure 1. Picture and schematic diagrams of the pressure transduction mechanism. (a) Resistive type. Reproduced with permission from [38], Copyright (2018), American Chemical Society. (b) Capacitive type. Reproduced with permission from [39], Copyright (2019), American Chemical Society. (c) Piezoelectric type. Reproduced with permission from [40], Copyright (2018), Royal Society of Chemistry.

\subsection{Resistive Type}

The sensing mechanism of a resistive pressure sensor is based on the variation of resistance under applied pressure (Figure 1a). Resistive pressure sensors have been widely studied due to their simple structure, high sensitivity, and wide measurement range. In resistive pressure sensors, the contact resistance between two conductive layers under applied pressure is usually measured. In these sensors, structured conductive layers are typically fabricated. The contact resistance between the electrodes decreases under external pressure because more parts of the active layer come into contact with each other. Coating an as-prepared porous structure with a conductive material is one of the simple ways to obtain a conductive porous structured active layer. Various conductive porous structures have been simply formed using reduced graphene oxide (rGO) with polyurethane (PU) sponge [41], $\mathrm{Au}$ NWs with tissue paper [42], rGO, fabric coated with graphene or CNTs [43-45], and single-walled carbon nanotubes (SWCNTs) have been coated on an M13 bacteriophage [46]. The sensitivity of a pressure sensor could also be enhanced with micro-patterned PDMS which is coated by conductive materials [47-49]. In addition, combining conductive materials such as CNTs [50], multi-walled carbon nanotubes (MWCNTs) [51], rGO [52], and Cu NWs [53] with other highly-deformable materials can help modify the performance of pressure sensors. Randomly-oriented electrospun nanofibers (NFs) have also been used as porous structures to enhance the sensitivity, detection limit, and response time of sensors [54-56]. Electrospinning technique will be briefly discussed in Section 3.

In order to fabricate the sensing layer of the resistive pressure sensors, not only chemical vapor deposition but also simple methods such as dip-coating, spray-coating, and drop-casting have been widely used. However, since metals such as silver and gold are generally used, and nano-powders with a size of tens to hundreds of nanometer are used, the material is generally expensive. In addition, for sufficient repeatability, measures to mitigate permanent deformation of the sensing layer are also required. 


\subsection{Capacitive Type}

A dielectric layer of a capacitive type pressure sensor plays a critically important role in achieving high sensitivity (Figure 1b). The capacitive pressure sensor is usually based on a parallel plate capacitor, and the capacitance is defined by the equation: $C=\varepsilon_{0} \varepsilon_{r} A / d$, where $\varepsilon_{0}$ and $\varepsilon_{r}$ are the dielectric constants of the vacuum and the dielectric layer, $A$ is the overlapped area of the two electrodes, and $d$ is the distance between the electrodes. When pressure is applied on the sensor, the dielectric layer deforms, i.e., $d$ changes, resulting in variation in the capacitance value.

PDMS and Ecoflex are often used as the dielectric materials of the capacitive pressure sensor due to their highly deformable nature [57-61]. Moreover, by modifying the surface of the dielectric layer with microstructures [62], micropillar arrays [63], wrinkled patterns [64], and pyramidal shapes [65,66], the sensitivity of the sensor can be dramatically enhanced. These patterns of various shapes not only improve the deformability of the dielectric layer, but also vary the effective dielectric constant $\left(\varepsilon_{r}\right)$, resulting in more variation in the capacitance. The pores between patterns are occupied by air, and their volumes are reduced by external pressure due to the deformation of the patterns. In general, since the permittivity $\varepsilon_{r}$ is greater than that of the air, as the portion of the air decreases, the effective dielectric constant increases, and consequently, the capacitance increases. With the synergetic effect of enhanced deformability of the dielectric layer and the varied effective dielectric constant, the sensitivity of the sensor can be dramatically enhanced. However, the surface modification method generally causes the pattern to collapse even at small pressure because the size of the pattern is typically only a few tens to hundreds of micrometers. It has high sensitivity until the pattern collapses, but the range is relatively short. In addition, since mold manufacture through photolithography is usually used, it is disadvantageous in terms of fabrication cost. However, once the mold is manufactured, it can be used semi-permanently and shows excellent reproducibility as long as the mold is not damaged.

Another way to improve the deformability of the dielectric layer is to form porous structures $[67,68]$. Park et al. introduced the fabrication strategy of using porous Ecoflex with a particle template method [69]. In this work, a sugar cube containing Ecoflex was cured, and then the cube was dissolved with hot water to obtain porous structures. Kang et al. described a particle template method with polystyrene (PS) beads as a sacrificial material and PDMS as a dielectric material [70]. PS beads were dissolved in dimethylformamide (DMF) for $12 \mathrm{~h}$, and the fabricated pressure sensor with porous structures showed a sensitivity of $0.63 \mathrm{kPa}^{-1}$, which is 7.85 times higher than a bare PDMS dielectric layer. To fabricate a porous structured elastomer, Lee et al. first prepared an emulsion of water and PDMS [71]. The phase of water changed from liquid to gas during the curing process to form micro-sized pores, and the PDMS was simultaneously cured, while the pores were trapped in the layer. Our group introduced using fluorocarbon (FC-43) with the emulsion template method, and the highly sensitive capacitive pressure sensor with a sensitivity of $1.43 \mathrm{kPa}^{-1}$ could be obtained [72]. Yang et al. achieved a great enhancement in sensitivity by using porous pyramidal patterned PDMS [73]. The deformability of the dielectric layer was further modified with both surface structures and porous structures, resulting in an extremely high sensitivity of $44.5 \mathrm{kPa}^{-1}$. Furthermore, the sensitivity of the porous structure-based capacitive pressure sensor can be further improved with a composite dielectric layer combined with Ag NPs [74], Cu/Ni NFs [39], carbon paste [75], and CNTs [76]. The porous structure has a wide measurement range because pores are spread throughout the entire dielectric layer. It can be manufactured through a simple and inexpensive method; however, the sensitivity of the sensor is relatively low, resulting in a relatively high detection limit.

\subsection{Piezoelectric Type}

The working principle of a piezoelectric type pressure sensor is that dipole moments in the active material result in the production of electrical potential (Figure 1c). The piezoelectric pressure sensor shows a high resolution, fast response, and high sensitivity. Due to a relatively high piezoelectric characteristic (piezoelectric voltage coefficient, $g_{33}$ ), low impedance, and good flexibility, polyvinylidene fluoride (PVDF) and its copolymers were widely used [77]. Composite materials are often used in 
the production of piezoelectric pressure sensors, as in the two types mentioned above. In particular, $\mathrm{BaTiO}_{3}$ has often been used as a combined material to enhance the electrical performance of piezoelectric pressure sensors $[40,78-80]$. However, PVDF has a relatively low piezoelectric charge coefficient $\left(d_{33}\right)$, resulting in a relatively low pressure sensitivity. On the other hand, inorganic materials, such as $\mathrm{ZnO}$, $\mathrm{GaN}, \mathrm{InN}, \mathrm{ZnS}$, and CdS has a high $d_{33}$ and are thus more frequently applied in pressure sensors [81-83].

The above-mentioned structured active layers for resistive and capacitive pressure sensors were also actively introduced to enhance the sensitivity of the piezoelectric pressure sensor [84-88]. Since these structured layers experience more deformation under external pressure, more charges are generated from the devices. Meanwhile, the electrospinning technique is widely used as a fabrication method for a piezoelectric pressure sensor. In particular, composite electrospun NFs have been extensively introduced because their combined particles are oriented along with the NFs due to the strong electric field force during electrospinning [89-94]. In addition, piezoelectric pressure sensors can be easily applied as self-powered sensors because they generate current and voltage by moving electrons when the sensor is placed under pressure. Self-powered pressure sensors are very attractive in the field of wearable electronics because they do not require an additional power source or energy storage device, such as a battery. However, since the materials used for piezoelectric pressure sensor have poor stretchability, their applications in wearable electronics have been limited.

\subsection{Other Types}

Other transduction mechanisms have also been utilized to sense external pressure. The transistortype pressure sensor is a good candidate for a highly-sensitive pressure sensor. Transistors are mainly studied for organic field-effect transistors, and their sensitivity is defined by the deformability of the gate dielectric layer under applied pressure, similar to capacitive-type pressure sensors [95-97]. Similarly, various methods have been introduced to improve the deformability of the dielectric layer. Wang et al. fabricated a pyramidal PDMS dielectric layer with a photolithography-based silicon mold, and the sensor showed an extremely high sensitivity of $514 \mathrm{kPa}^{-1}$ [98]. In addition, materials with excellent deformability, such as PDMS and Ecoflex, have been widely used $[99,100]$.

The triboelectric sensor is another type of promising self-powered pressure sensor. Triboelectric pressure sensors are based on triboelectric nanogenerators (TENGs), whose mechanism is based on the coupling effect of triboelectrification and electrostatic induction. For TENGs, the contact/separation mode is mainly used, with two dielectric layers. To optimize the triboelectric effect, dielectric materials located at the opposite ends of the triboelectric series are demanded. In addition, a larger surface area of the dielectric layer is preferred to induce more charges on their surface. Silicon molds with pyramidal structures are widely used to increase the surface area of the dielectric layers [101-104]. However, a silicon mold is usually produced with a complex and time-consuming process. As a method of using a low-cost mold rather than a silicon mold, Rasel et al. introduced a sandpaper mold to modify the surface of the layer, resulting in a sensitivity of $0.51 \mathrm{~V} / \mathrm{kPa}$ [105]. Yao et al. used a C. zebrine leaf as a mold, and the sensitivity of the pressure sensor was boosted with a 14-fold increase compared with a flat surface [106]. Electrospun NFs are also frequently employed due to their fast and simple fabrication process, as well as the high surface area of the NFs [107-110].

\section{Fabrication Technologies}

To improve the electrical performances of pressure sensors, various fabrication processes have been introduced. In recent years, flexibility and stretchability are also increasingly demanded for wearable electronics. Many studies are underway to meet these requirements, and various fabrication methods including a dielectric layer, a conductive layer, and a piezoelectric layer will be covered in this section. 


\subsection{Porous Structures}

A porous structure is used in almost all types of pressure sensors because it can broaden the surface area and improve the deformability by lowering the the density and Young's modulus of the layer. In this section, electrospinning, particle template, and emulsion template will be covered.

Electrospinning is a promising fabrication technique to produce nano- and micro-sized nanofibers (Figure 2). The NFs promise sufficient deformability even if the material is relatively brittle. In the electrospinning, a polymer solution is ejected from a nozzle by applying a high voltage to the nozzle, and the collector is grounded. After ejection, the jet experiences a whipping instability and extension before deposition due to interactions between charges existing in the jet, resulting in randomly deposited NFs. The electrospun fibers have a rough surface and remarkably large surface area per unit volume. Moreover, the electrospun NF layer has excellent deformability compared to the bulk PDMS layer. Our group has introduced an electrospun NF-based capacitive pressure sensor [111]. An electrospun PVDF-TrFE NF layer exhibited a stiffness 6 times lower than that of a spin-coated PDMS layer. Sharma et al. fabricated MXene composite nanofibrous scaffolds via electrospinning [112]. The fabricated sensor demonstrated a high sensitivity of $0.51 \mathrm{kPa}^{-1}$ and a minimum detection limit of 1.5 Pa. In addition, the sensor showed stable output signals for 10,000 cyclic tests under pressure of $167 \mathrm{kPa}$. Chen et al. produced PVDF NFs to fabricate a dielectric layer of a TENG [107]. In this work, polarized PVDF NFs showed higher electrical performances compared to flat-surface PVDF layers and unpolarized PVDF NFs. Core-shell NFs of a PDMS ion gel/PVDF-HFP was first introduced by Lin et al., and the sensitivity with this NF mat was $0.43 \mathrm{kPa}^{-1}$ [108]. Electrospinning is rarely used for resistive pressure sensors because a high voltage difference of a few $\mathrm{kV}$ is induced between the nozzle and ground collector. In addition, electrospinning can only use materials with a high molecular weight.

(a)

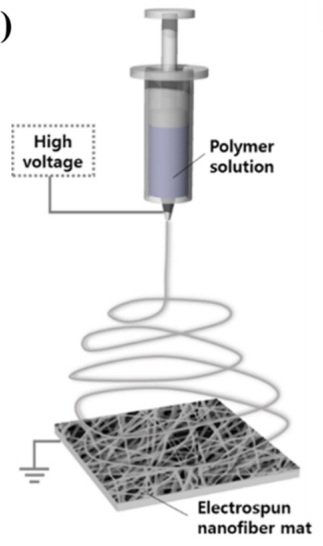

(c)

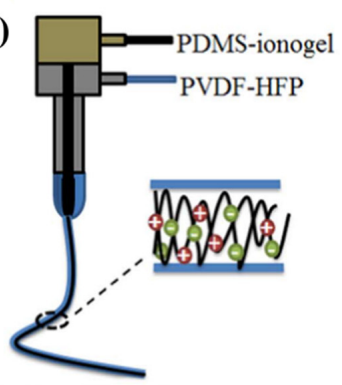

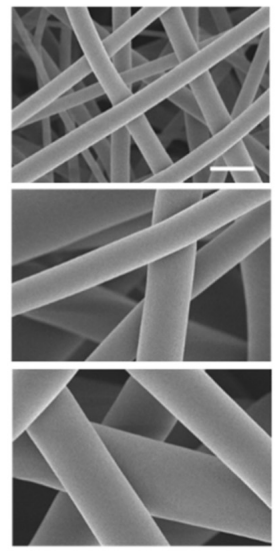

(b)
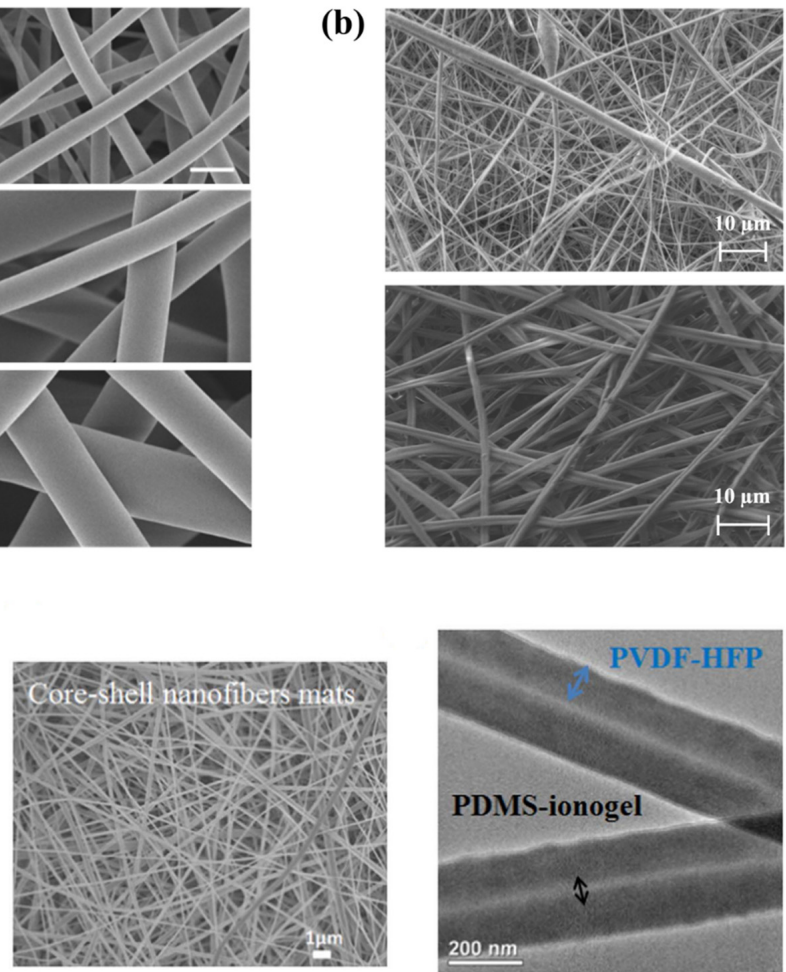

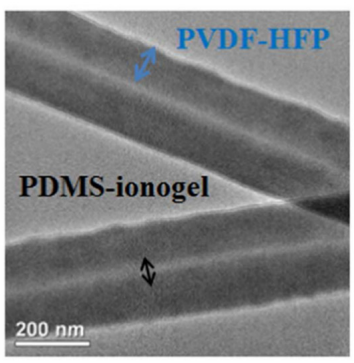

Figure 2. Schematic of electrospinning technique and SEM images of electrospun NFs. (a) Electrospun PVDF-TrFE NFs at different solution concentrations of 14,18 , and $22 w / v \%$ from the top to bottom of images. Reproduced with permission from [90], Copyright (2016), American Chemical Society. (b) Electrospun NFs of PVDF and PVP. Reproduced with permission from [113], Copyright (2018), Elsevier. (c) Schematic diagram of core-shell electrospinning technique and SEM images of NFs. Reproduced with permission from [108], Copyright (2018), Elsevier. 
The particle template method is one of the simple ways to produce porous structures $[39,67-70,75,76]$. The easily dissolvable particles, such as sugar and $\mathrm{NaCl}$, are first mixed with a matrix material, which is usually silicone rubber (Figure 3). After the matrix material is cured, the particles are dissolved and removed to complete all fabrication processes. The particle dissolving process requires a long duration of several hours to more than $24 \mathrm{~h}$, but as a relatively simple method, even a person without proper training can sufficiently secure reproducibility with the particle template method. Xiong et al. used this method to produce a PDMS mold with a PS bead as a dissolvable particle [114]. Another PDMS layer was produced via the PDMS mold, and Au was sputtered on the new PDMS layer. The spin-coated PVDF layer was then sandwiched between two PDMS layers. The sensor showed a sensitivity of $30.2 \mathrm{kPa}^{-1}$ which is sufficient to measure pressure of $0.7 \mathrm{~Pa}$.

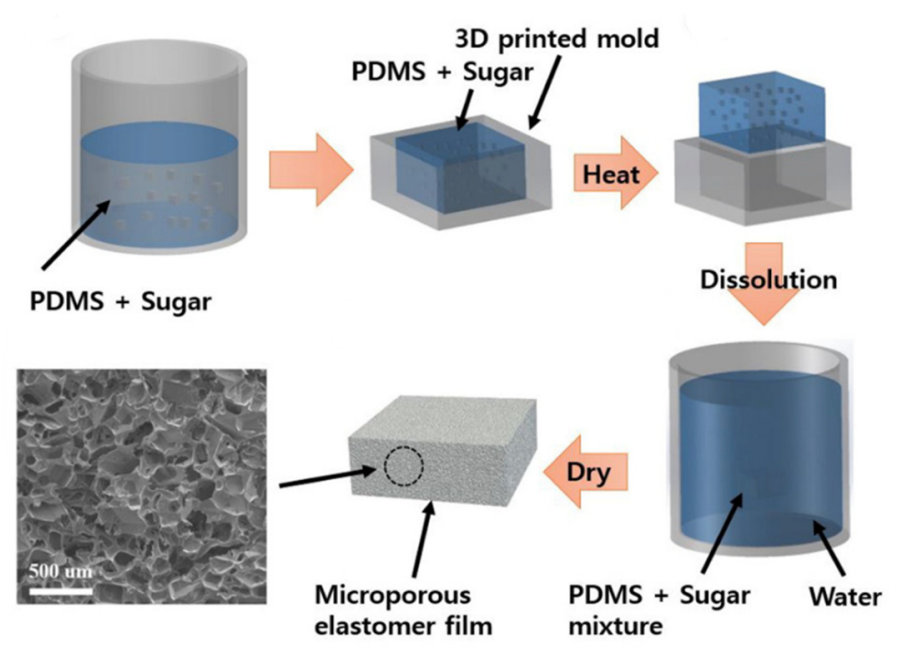

Figure 3. The typical fabrication process of the particle-template method. Reproduced with permission from [67], Copyright (2017), Elsevier.

To implement the emulsion template method, two or more aqueous solutions should be homogeneously mixed. For example, a fluorocarbon (FC-43) dispersed PDMS emulsion was used to fabricate a porous structured PDMS layer for TENG and capacitive pressure sensor applications by our group (Figure 4) [72,115]. In this work, the rapid fabrication of the porous structure was the key factor. A microwave-irradiated PDMS emulsion is cured in $3 \mathrm{~min}$, and the dispersed phase (FC-43) is evaporated simultaneously. The volume of FC-43 rapidly increases during the phase change and is trapped in a PDMS layer due to its fast curing. The capacitive pressure sensor with emulsion-templated porous PDMS showed a sensitivity of $1.43 \mathrm{kPa}^{-1}$, which is 20 times higher than a non-porous PDMS layer. Through the emulsion template method and microwave irradiation, the rapid fabrication of porous PDMS is possible, but limited solutions can only be homogenously dispersed in a PDMS solution. This limitation applys similarly to all emulsion template methods, but unlike the particle template method, there is no need for post-processing because pores are formed simultaneously with curing of the matrix material. 
(a)
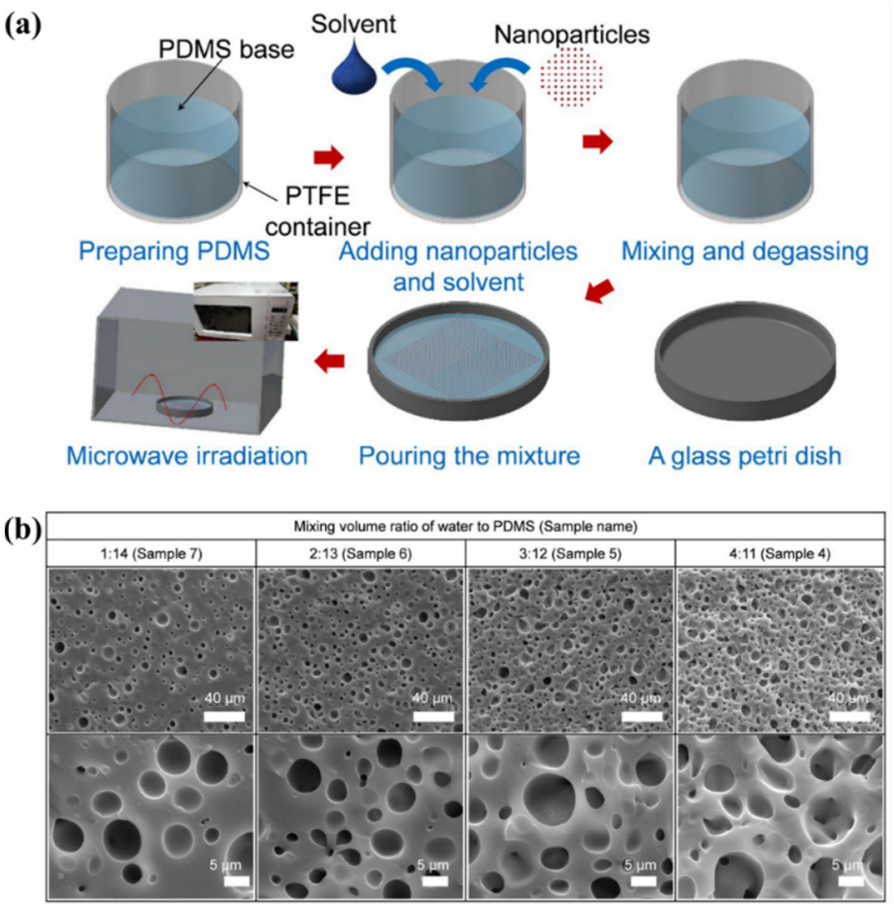

Figure 4. (a) Typical fabrication process of the emulsion-template method and (b) the cross-sectional SEM images of porous PDMS. Reproduced from [115].

\subsection{Surface Modification}

Surface modification aims to produce a pattern of special shape confined to the active layer surface. These patterns have a high aspect ratio and use a mold produced through photolithography or soft-lithography. Pyramid or rod patterns are widely used to enhance deformability and surface area of the active layer surfaces (Figure 5). For resistive pressure sensors, the surface of the soft active layer, including patterns, is coated with conductive materials, such as $\mathrm{Pt}[116]$, poly $(3,4-$ ethylenedioxythiophene):poly(styrenesulfonate) (PEDOT:PSS) [117], and rGO [118]. Since the contact surface of the two electrodes becomes larger under external pressure, the deformability of the pattern should be improved for larger variation in resistance [116-118]. Kim et al. introduced a sandblasted silicon mold to fabricate vertically-aligned CNTs on a PDMS substrate. As a resistive pressure sensor, it showed a sensitivity of $0.3 \mathrm{kPa}^{-1}$ at pressure $<0.7 \mathrm{kPa}$. Lee et al. used micropatterned PDMS as a dielectric layer of a triboelectric tactile sensor [101]. The micropatterned PDMS was developed on various polymer foams, such as PU, ethylene vinyl acetate (EVA), and polyvinyl chloride (PVC). Among these polymer foams, PVC showed the highest sensitivity of $14.3 \mathrm{mV} / \mathrm{kPa}$, but it had the narrowest measurement range. Yang et al. introduced a novel fabrication method for porous pyramidal patterns [73]. Porous structures could be obtained with a particle template method with PS beads, and the pyramidal patterns were fabricated with a silicon mold. The PS beads were stacked in and on the pyramid-patterned mold, and then the PDMS solution was spin-coated. Under sufficient pressure during the curing process, a porous pyramidal PDMS dielectric layer could be obtained. The capacitive pressure sensor with this dielectric layer has a sensitivity of $44.5 \mathrm{kPa}^{-1}$ which is $10-20$ times higher sensitivity compared to other capacitive pressure sensors. 

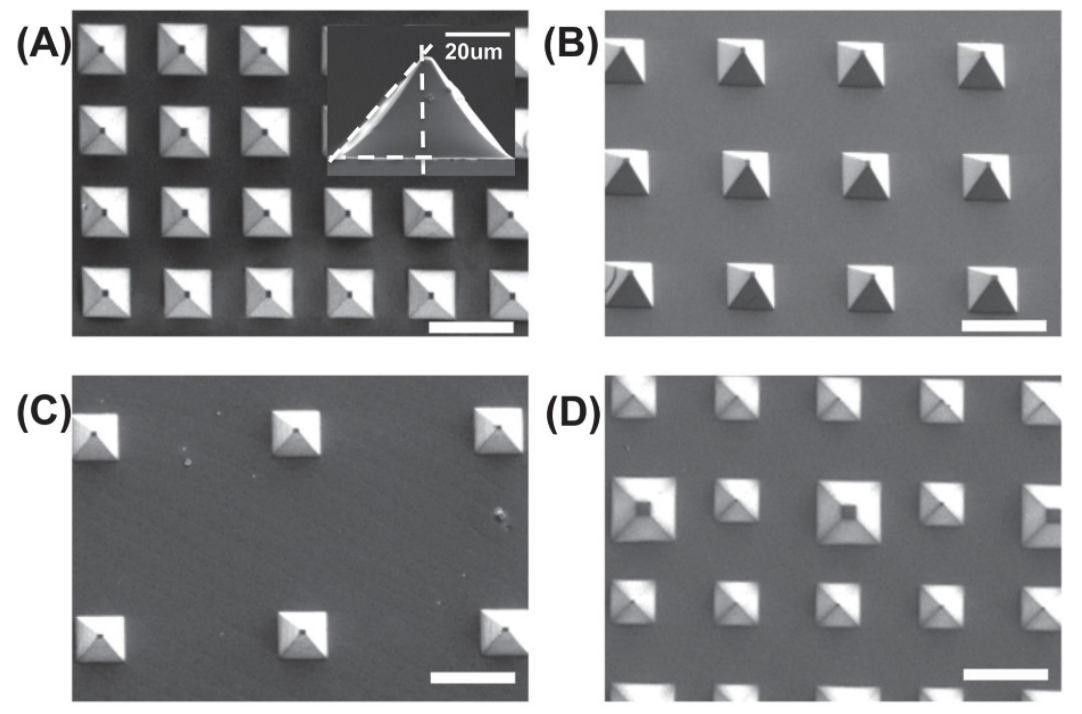

Figure 5. Pyramidal patterns on PDMS layer transferred from the silicon mold (scale bars are $100 \mu \mathrm{m}$ ). (A) Spacing of $41 \mu \mathrm{m}$, (B) $88 \mu \mathrm{m}$, (C) $182 \mu \mathrm{m}$ and (D) interspersed design of two pyramidal structures with different based area. The inset in the upper left image shows the cross-section of a pyramidal structure. Reproduced with permission from [66], Copyright (2014), Wiley-VCH.

Readily market-available molds, rather than specially prepared molds, or even the leaves of trees, have also been used to modify the surface of the active layer. Su et al. used a mimosa leaf as a mold to fabricate a leaf replica for a resistive pressure sensor [47]. Two gold-deposited replicas were assembled to construct a resistive pressure sensor, and it showed a sensitivity $50.17 \mathrm{kPa}^{-1}$. This work is significant in that it has produced a highly sensitive pressure sensor using an uncomplicated and low-cost process. Wang et al. produced sandpaper-based PDMS microhump patterns [49]. The patterns were then coated with PEDOT:PSS to fabricate a contact-resistance-based resistive pressure sensor. This sensor showed a remarkably high sensitivity of $851 \mathrm{kPa}^{-1}$ at $<3 \mathrm{kPa}$. The fabric is another patterned structure that is commercially available around the world. Using the fabric as a mold to improve the surface roughness of the sensing layer can be simplified at a low cost. Wang et al. used a silk mold to obtain a patterned PDMS surface and investigated the effect of the pattern density on the sensitivity of the resistive pressure sensor [119]. The results indicate that a higher pattern density is more advantageous due to its more effective contact sites, which leads to larger charge transfer when pressure is applied. To optimize the geometry of the pyramidal pattern for high sensitivity, Liang et al. presented an analytical model that investigated the structural effects of the patterns [120]. From the results of this work, the compressive deformation of the pyramidal patterns increases as the height of the pyramid increases, and the bottom length of the pyramid decreases. That is, the high aspect ratio of the patterns leads to more deformation of the patterns under the same applied pressure, resulting in higher sensitivity for any type of pressure sensor.

Wrinkled patterns can be fabricated by ultra-violet ozone (UVO) radiated elastomers. UVO radiation on a cured elastomer film leads to silicon oxide layers several $\mathrm{nm}$ thick. When the strain is removed, the silicon oxide layer is buckled, showing wrinkled patterns. Baek et al. used a PDMS dielectric layer with wrinkled patterns for the capacitive pressure sensor [121]. The double-sided wrinkled pattern increased the sensitivity up to $0.013 \mathrm{kPa}^{-1}$. Shuai et al. used a wrinkled structure elastomer as a mold. The Ag NWs drop-casted on the stretched PDMS after the UVO radiation, and then the PDMS solution was poured onto the Ag NW-coated PDMS mold. After the PDMS solution underwent a curing process, an Ag NW-embedded wrinkled PDMS layer can be obtained. Spin-coated PVDF is further used as a dielectric layer, and the pressure sensor showed a high sensitivity of $2.94 \mathrm{kPa}^{-1}$, due to the easily-deformed Ag NW electrode. 


\subsection{Printing Methods}

The printing technique has gained the most attention for future applications due to its low material wastage, the capability of large-area production, and low cost. Recently, an additive manufacturing technology that can print plastics, as well as metals, has emerged in various fields [122]. Leigh et al. fabricated 3D structure using carbon black (CB)/polycaprolactone (PCL) composite [123]. The CB/PCL based resistive pressure sensor could detect finger motion. The author also demonstrated a "smart" vessel. They produced a cup containing two conductive traces acting as a capacitor. The capacitance value increases as the amount of water in the cup increases. Zhuo et al. fabricated a 3D-printed mold to enhance the deformability of the PDMS dielectric layer [23]. The capacitive pressure sensor with micropatterned PDMS showed a sensitivity of $1.62 \mathrm{kPa}^{-1}$. These results are meaningful for the development of electronic devices of various shapes, film-like thin sensors, and for pioneering wider applications.

Solution-based printing methods, such as screen printing, roll-to-roll printing, offset printing, gravure printing, and inkjet printing are also used in this field [124]. Inkjet-printed PDMS can directly act as a pattern, such as a pyramidal pattern, and the control of various experimental variables such as dot size, the distance of each dot, the number of overprinting, and printing speed is much simpler than other surface modification methods. Peng et al. produced inkjet-printed PDMS micropatterns and investigated the effect of pattern distance on the pressure sensitivity (Figure 6) [125]. The sensitivity was improved as the pattern distance increased due to the enhanced deformability. In addition, this device was able to fabricate TENG simply by changing the structure of the device and successfully produced an output voltage of $1.23 \mathrm{~V}$.
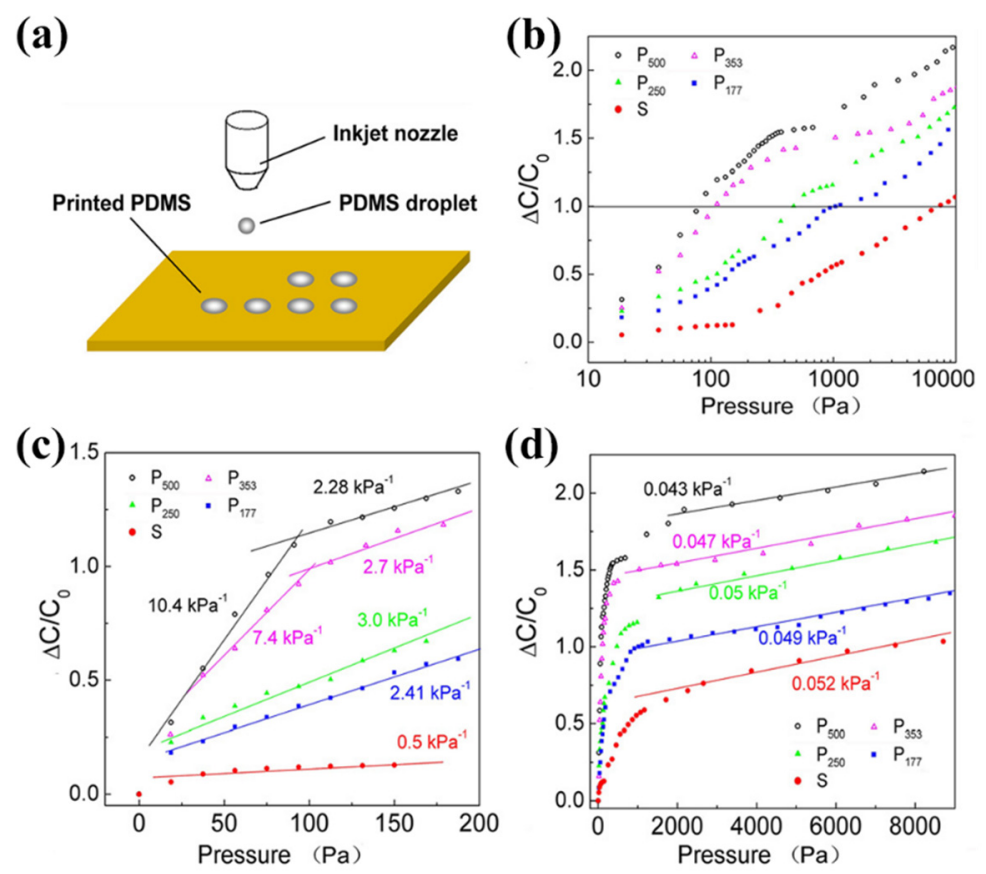

Figure 6. Inkjet printing-based microstructured PDMS. (a) Schematic diagram of inkjet-printed PDMS droplet and $(\mathbf{b}-\mathbf{d})$ the capacitance change ratio of the sensor with respect to pattern distances under pressure range of $0-10 \mathrm{kPa}, 0-200 \mathrm{~Pa}$, and 2-8 $\mathrm{kPa}$, respectively. Reproduced with permission from [125], Copyright (2017), AIP publishing.

\subsection{Other Methods}

Aside from the fabrication methods mentioned above, other techniques have also been utilized to fabricate pressure sensors. Dip-coating is a widely used coating method because it is a simple, easy to handle, and fast fabrication method [41-43,45,46,126]. Especially, dip-coating is often used to 
fabricate the conductive layer for resistive pressure sensors because the sensing layer of the resistive type sensor should be entirely conductive, unlikely the active layers of other types. However, in order to make a conductive layer by using dip-coating, repeated coating has to be performed to obtain sufficient conductivity.

Spin-coating and spray-coating are fabrication methods that focus more on surface treatment [127-129]. The disadvantage is that only low-viscosity solutions can be used, but several variables can be easily controlled to produce thin films quickly and easily [58,62,130-134]. Zhou et al. introduced an interesting spin-coating method that produces a magnetically induced coating to replicate human skin and the sensing mechanism of hairs [135]. The PDMS solution is first spin-coated and cured on a glass substrate. Carbonyl iron particles (CIP) are dispersed in the PDMS solution which is then spin-coated on PDMS/glass substrate. The uncured CIP/PDMS solution is turned into micro cilia array (MCA) under a magnetic field induced by a permanent magnet. After the curing process, the MCA can be obtained on a PDMS substrate. With this structure, the sensor showed a high sensitivity of $0.28 \mathrm{kPa}^{-1}$. Table 1 provides comprehensive information regarding pressure sensors for an easy comparison of the various approaches.

Table 1. Summary of some pressure sensors and their electrical performances.

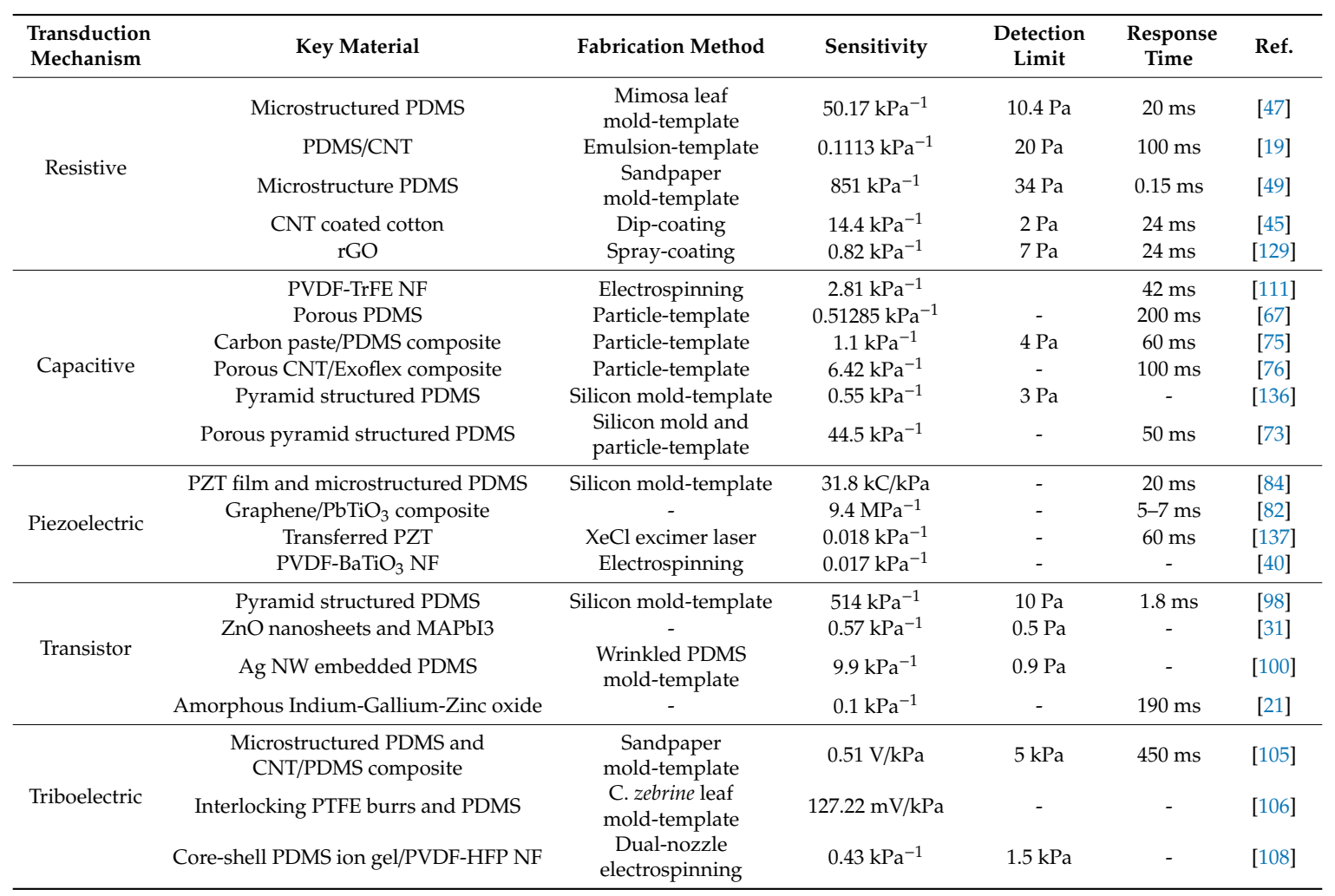

\section{Applications of Flexible Pressure Sensors}

\subsection{Human-Machine Interfaces}

Human-machine interfaces and remote control of robots can be effectively applied in the field of surgery or risky situations [138]. Several companies have produced surgical robots that are already being used to help doctors perform surgery. Until now, these robots are usually used to prevent hand tremor, but it is expected that the interaction between the robot and the surgeon would be possible. High sensitivity is essential for precise information transfer between humans and machines, and for this purpose, the measurement range corresponding to each use should be properly adjusted. Through this application, even when it is difficult for the doctor to physically access the patient, the operation can be remotely performed in the future. In these applications, the pressure sensors are attached to the 
machine or human body $[139,140]$. In general, the sensors are mounted on the parts that have a large degree of deformation such as fingers, elbows, or knees. Moreover, sensors are also usually attached to the part where a large pressure is typically applied, such as the fingertips or soles. Therefore, the sensors for human-machine interfaces are required to have sufficient stretchability and a large measurement range with stable output signals.

A textile-based capacitive pressure sensor was demonstrated to be applied for human-machine interfaces as a wearable electronics (Figure 7) [141]. Four channels of capacitive pressure sensors were attached on four fingers (the index, middle, ring, and little fingers) and on the forearm portion of clothes. A remotely operated drone was controlled by the smart glove, and a hexapod robot was also operated with the sensors. Different commands were set for each channel, and as a result of the experiment, it was confirmed that the sensors work well. From these results, the proposed textile-based capacitive pressure sensors have sufficient capability to be used for human-machine interfaces. As described above, many studies have been conducted to apply their pressure sensors to human-machine interfaces [106,142-145].
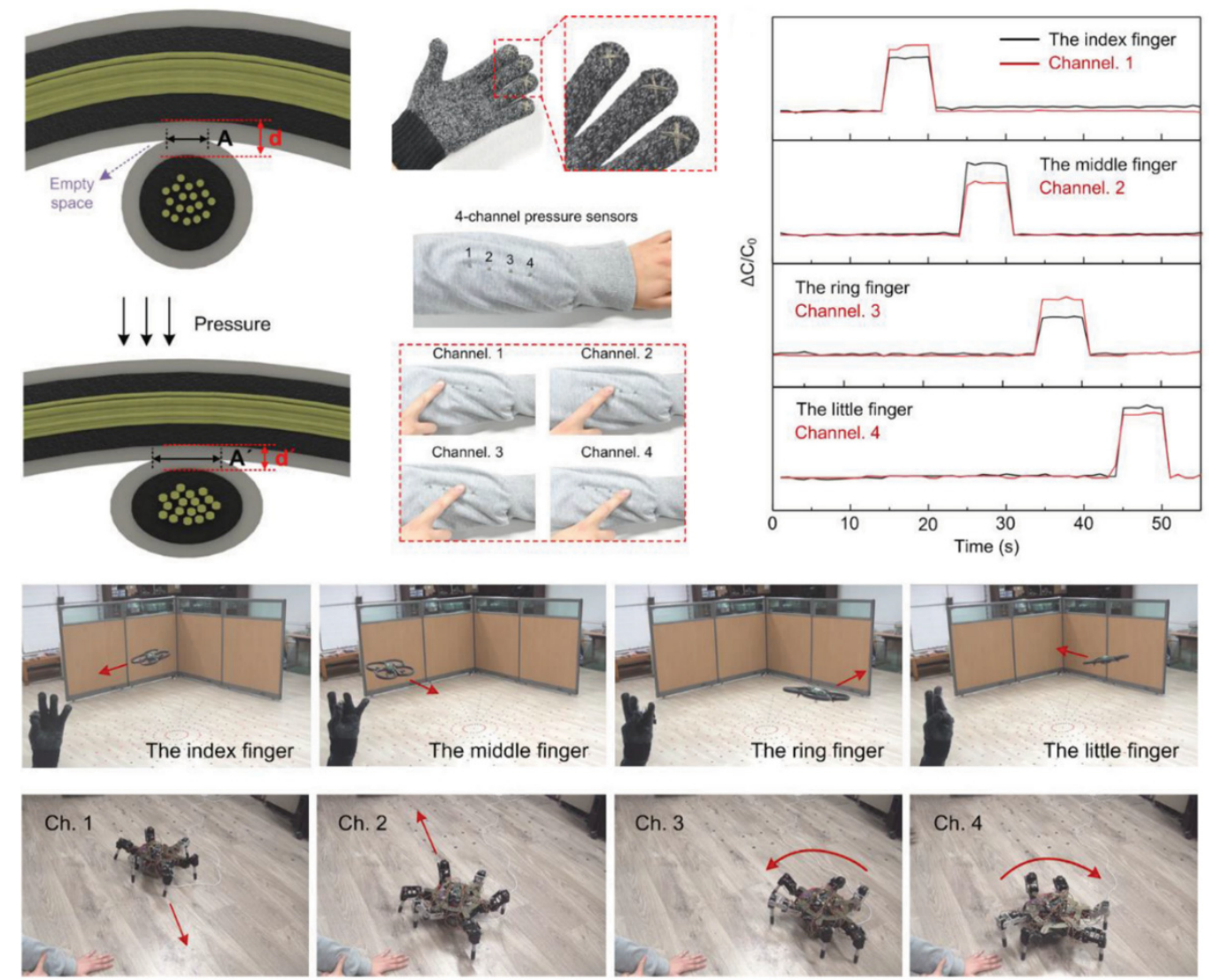

Figure 7. Remote control of a robot using pressure sensors for human-machine interfaces. Reproduced with permission from [141], Copyright (2015), Wiley-VCH.

\subsection{Biomedical Pressure Sensing}

Pressure sensors should have sufficient sensitivity to be used as a health monitoring system because biomedical pressure is usually very small on human skin. Biomedical signals, such as the pulse, blood pressure, respiration rate, and cardiac impulse play an important role in health monitoring (Figure 8). The sensors collect the wearer's health status in various ways so that rapid treatment can be taken during medical emergencies. In this case, the device should be properly attached to the human body and constantly receive information. Therefore, it is highly desired to be compact and small enough that the wearer is not uncomfortable, and sufficient sensitivity is required even in a small 
size. In addition, there are several restrictions because materials that are harmless to the human body should be used. Numerous studies have been conducted to implement pressure sensors as a health monitoring system [38,146-149].

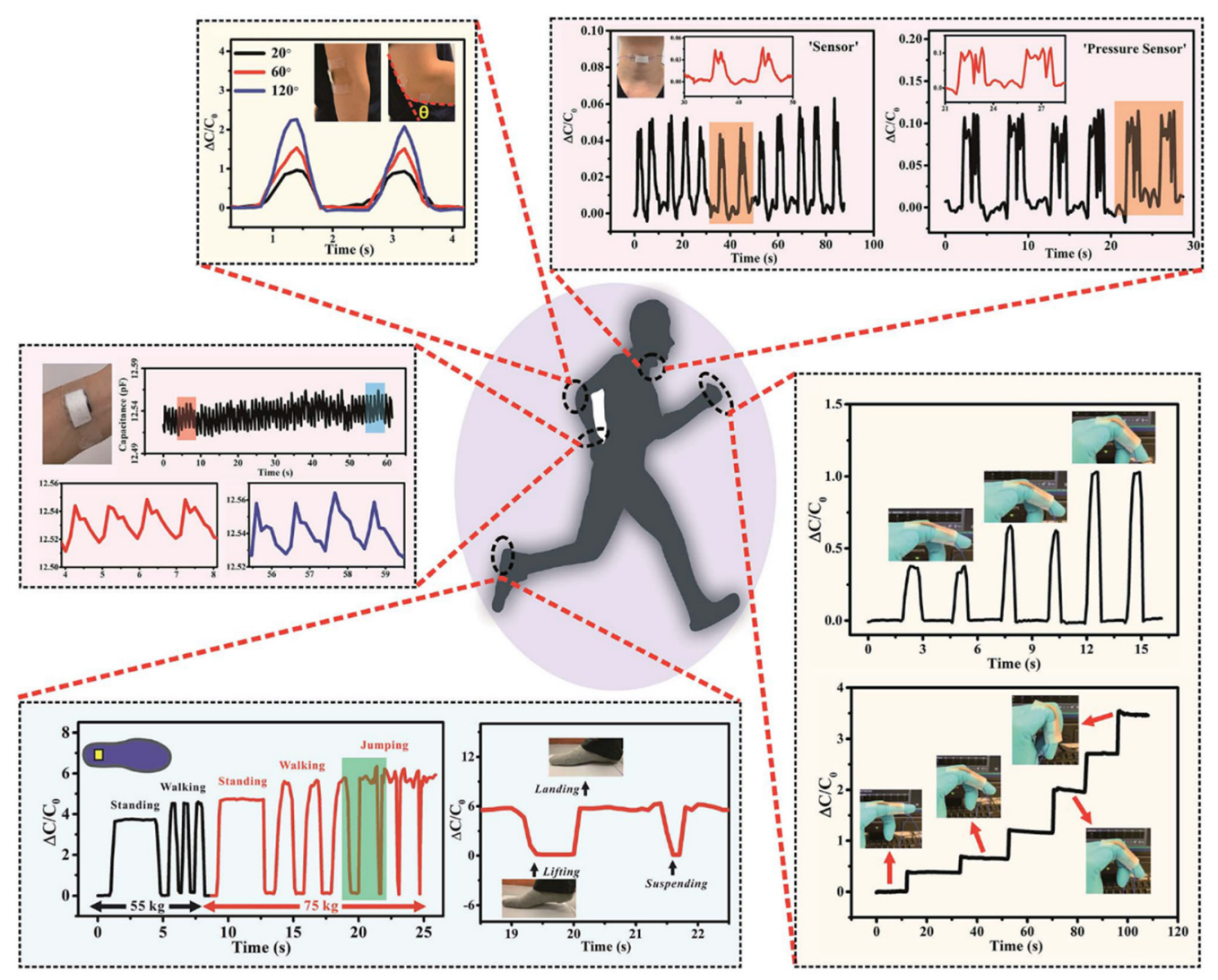

Figure 8. Biomedical applications for detecting various stimuli. Reproduced with permission from [135], Copyright (2019), Royal Society of Chemistry.

One promising way to configure a health monitoring system is to use self-powered pressure sensors $[108,150,151]$. This type of sensor does not require an additional power source, such as a battery, so the system can avoid becoming heavy enough to distract the human senses. Park et al. used their piezoelectric pressure sensor as a self-powered real-time arterial pulse monitoring system [137]. The signal obtained from the sensor was able to clearly distinguish whether or not the user had recently exercised. In addition, carotid artery pulses and the respiration rate were also clearly detected. One thing to note about these sensors is the use of biocompatible materials. Unlike human-machine interface applications, sensors must be attached directly to human skin to measure very small biomedical pressure. In addition, excellent robustness that can operate semi-permanently is also required.

\subsection{Pressure Distribution}

A sensor array is required to measure the pressure distribution (Figure 9). This method often analyzes the distribution of pressure applied to an array with an irregular shape. However, the pressure distribution in wearable electronics should aim to measure the distribution on the human body. For this purpose, the sensor needs excellent flexibility and stretchability. The sensor array is expected to be applied to various fields such as sports, ergonomic furniture and clothing, and motorsports. In particular, since it can be used as data for posture control by analyzing information collected from sensor cells, it can be widely used in the sports field. For this, reproducibility is indispensable in sensor manufacturing, and sometimes, since repetitive external force is applied in a harsh environment, mechanically robust design and manufacture are also demanded. Since sensors are designed to contain 
electrode materials, making the flexible electrodes is also a major research topic [72,152-168]. Of course, $\mathrm{CNT}, \mathrm{rGO}$, and metal NWs already show excellent performance as flexible electrode materials, but the above materials are relatively expensive and difficult to manufacture.

(a)
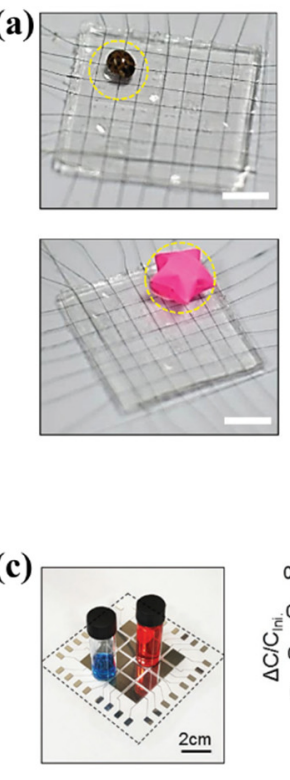
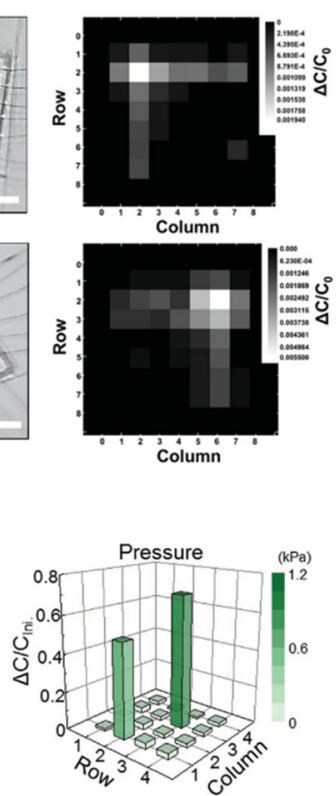

(b)

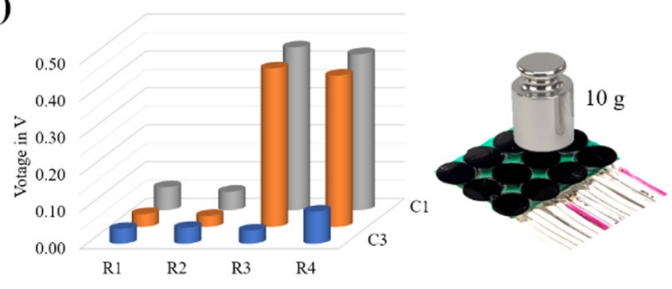

(d)
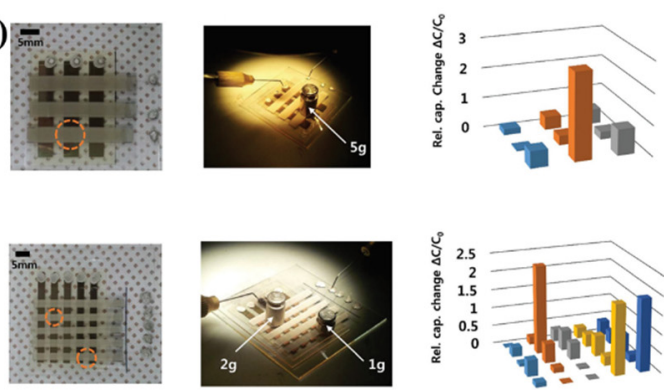

Figure 9. Various types of sensor arrays. (a) CNT microyarn-based sensor array. Reproduced with permission from [153], Copyright (2015), Wiley-VCH. (b) MWCNT/PDMS composite. Reproduced from [140]. (c) SWCNT-embedded PDMS with pyramidal patterns. Reproduced with permission from [154], Copyright (2018), Wiley-VCH. (d) Ag NW-embedded wavy PDMS. Reproduced with permission from [134], Copyright (2015), Royal Society of Chemistry.

Kim et al. used liquid metal to produce pressure sensitive microfluidic channels with eutectic gallium indium (EGaIn) [169]. An initially-printed EGaIn line pattern on stretchable substrate was strained with the substrate, and it was transferred onto another non-strained stretchable substrate. By repeating this process several times, a sub- $2 \mu \mathrm{m}$ pattern could be obtained. For the fabrication of a sensor array with these features, 3-10 $\mu \mathrm{m}$ patterns were fabricated with 4 horizontal and 4 vertical EGaIn lines, and the array showed excellent response under applied pressure.

\section{Conclusion and Future Perspectives}

In this review, recent progress in flexible pressure sensors was introduced, covering their transduction mechanisms, fabrication methods, and applications. The pressure sensor is one of the most demanded electronic devices in wearable electronics, artificial skin, and other fields. Various studies have been conducted, and substantial effort has been devoted to enhancing the electrical performance of sensors. Excellent electrical performance, especially high sensitivity, can broaden the application of the device.

Regardless of the type of sensor, the future trends of sensor development mainly focus on the following aspects. First, high electrical performance, including sensitivity, response time, detection limit, and mechanical durability with a wide measurement range, is necessary. In general, highly-sensitive pressure sensors have a very small detection limit, but a narrow measurement range. In order to apply these sensors to wearable electronics with various quantities of external stimuli, it is essential to have a high sensitivity and a wide measurement range. In addition, hysteresis should be sufficiently secured for easy calibration. The mechanical durability for long-term use should also be guaranteed. Second, a multifunctional sensor is required to meet the needs of applications in the fields of wearable electronics. Unlike a laboratory where the environment is precisely controlled, people's surroundings 
vary widely. Various external factors, such as humidity, temperature, vibration, etc., are present, and in order to produce truly wearable electronics, it is necessary to measure all external stimuli. In particular, although only the pressure sensor was covered in this review, the multifunctional sensor that measures both pressure and strain is required because they always act simultaneously on human skin. Third, self-powered sensors are a new trend in the field of wearable electronics in recent years. Piezoelectric and triboelectric pressure sensors are good candidates to realize this function. Overcoming the brittle properties of the piezoelectric materials is the main challenge for piezoelectric pressure sensors. The triboelectric pressure sensor further needs an increased power density. As wearable electronics develop, the device size and power requirements will decrease, but the triboelectric nanogenerator usually generates insufficient power density. In addition to the above trends of future developments, biodegradable and self-healing pressure sensors are desired for a wider range of wearable electronics applications. Further focused research is demanded to discover more flexible, stretchable and yet effective sensing materials. Moreover, to realize these diverse requirements, a novel fabrication method is likely required for future applications.

Author Contributions: Writing—original draft preparation, Y.K.; writing—review and editing, Y.K. and J.H.O.; supervision, J.H.O. All authors have read and agreed to the published version of the manuscript.

Funding: This work was supported by the National Research Foundation of Korea (NRF) grant funded by the Korea Government (MSIP) (No. 2019R1A2C1005023). This work was also supported by the research fund of Hanyang University (HY-2020-0389).

Conflicts of Interest: The authors declare no conflict of interest.

\section{References}

1. Brookhuis, R.A.; Lammerink, T.S.J.; Wiegerink, R.J.; de Boer, M.J.; Elwenspoek, M.C. 3D force sensor for biomechanical applications. Sens. Actuator A Phys. 2012, 182, 28-33. [CrossRef]

2. Ponce Wong, R.D.; Posner, J.D.; Santos, V.J. Flexible microfluidic normal force sensor skin for tactile feedback. Sens. Actuator A Phys. 2012, 179, 62-69. [CrossRef]

3. Wang, J.; Jiu, J.; Araki, T.; Nogi, M.; Sugahara, T.; Nagao, S.; Koga, H.; He, P.; Suganuma, K. Silver Nanowire Electrodes: Conductivity Improvement Without Post-treatment and Application in Capacitive Pressure Sensors. Nanomicro Lett. 2015, 7, 51-58. [CrossRef]

4. Liu, X.; Zhu, Y.; Nomani, M.W.; Wen, X.; Hsia, T.-Y.; Koley, G. A highly sensitive pressure sensor using a Au-patterned polydimethylsiloxane membrane for biosensing applications. J. Micromech. Microeng. 2013, 23, 025022. [CrossRef]

5. Dagdeviren, C.; Su, Y.; Joe, P.; Yona, R.; Liu, Y.; Kim, Y.S.; Huang, Y.; Damadoran, A.R.; Xia, J.; Martin, L.W.; et al. Conformable amplified lead zirconate titanate sensors with enhanced piezoelectric response for cutaneous pressure monitoring. Nat. Commun. 2014, 5, 4496. [CrossRef] [PubMed]

6. Wang, W.; Peng, D.; Zhang, H.; Yang, X.; Pan, C. Mechanically induced strong red emission in samarium ions doped piezoelectric semiconductor $\mathrm{CaZnOS}$ for dynamic pressure sensing and imaging. Opt. Commun. 2017, 395, 24-28. [CrossRef]

7. Watanabe, Y.; Uemura, S.; Hoshino, S. Printed pressure sensor array sheets fabricated using poly(amino acid)-based piezoelectric elements. Jpn. J. Appl. Phys. 2014, 53, 05HB15. [CrossRef]

8. Tsuji, Y.; Sakai, H.; Feng, L.; Guo, X.; Murata, H. Dual-gate low-voltage organic transistor for pressure sensing. Appl. Phys. Express 2017, 10, 021601. [CrossRef]

9. Wan, C.; Chen, G.; Fu, Y.; Wang, M.; Matsuhisa, N.; Pan, S.; Pan, L.; Yang, H.; Wan, Q.; Zhu, L.; et al. An Artificial Sensory Neuron with Tactile Perceptual Learning. Adv. Mater. 2018, 30, 1801291. [CrossRef]

10. Ha, D.; de Vries, W.N.; John, S.W.; Irazoqui, P.P.; Chappell, W.J. Polymer-based miniature flexible capacitive pressure sensor for intraocular pressure (IOP) monitoring inside a mouse eye. Biomed. Microdevices 2012, 14, 207-215. [CrossRef]

11. Kim, G.; Cho, S.; Chang, K.; Kim, W.S.; Kang, H.; Ryu, S.P.; Myoung, J.; Park, J.; Park, C.; Shim, W. Spatially Pressure-Mapped Thermochromic Interactive Sensor. Adv. Mater. 2017, 29, 1606120. [CrossRef]

12. Weadon, T.L.; Evans, T.H.; Sabolsky, E.M. Ceramic-polymer capacitive sensors for tactile/force awareness in harsh environment robotic applications. Smart Mater. Struct. 2013, 22, 125017. [CrossRef] 
13. Shao, N.; Wu, J.; Yang, X.; Yao, J.; Shi, Y.; Zhou, Z. Flexible capacitive pressure sensor based on multi-walled carbon nanotube electrodes. Micro Nano Lett. 2017, 12, 45-48. [CrossRef]

14. Ke, K.; McMaster, M.; Christopherson, W.; Singer, K.D.; Manas-Zloczower, I. Highly sensitive capacitive pressure sensors based on elastomer composites with carbon filler hybrids. Compos. Part A Appl. Sci. Manuf. 2019, 126, 105614. [CrossRef]

15. Nan, N.; DeVallance, D.B. Development of poly(vinyl alcohol)/wood-derived biochar composites for use in pressure sensor applications. J. Mater. Sci. 2017, 52, 8247-8257. [CrossRef]

16. Zhao, H.; Bai, J. Highly sensitive piezo-resistive graphite nanoplatelet-carbon nanotube hybrids/ polydimethylsilicone composites with improved conductive network construction. ACS Appl. Mater. Interfaces 2015, 7, 9652-9659. [CrossRef] [PubMed]

17. Kim, H.J.; Kim, Y.J. High performance flexible piezoelectric pressure sensor based on CNTs-doped 0-3 ceramic-epoxy nanocomposites. Mater. Des. 2018, 151, 133-140. [CrossRef]

18. Viry, L.; Levi, A.; Totaro, M.; Mondini, A.; Mattoli, V.; Mazzolai, B.; Beccai, L. Flexible three-axial force sensor for soft and highly sensitive artificial touch. Adv. Mater. 2014, 26, 2659-2664. [CrossRef]

19. Xu, M.; Gao, Y.; Yu, G.; Lu, C.; Tan, J.; Xuan, F. Flexible pressure sensor using carbon nanotube-wrapped polydimethylsiloxane microspheres for tactile sensing. Sens. Actuators A Phys. 2018, 284, 260-265. [CrossRef]

20. Ma, R.; Lee, J.; Choi, D.; Moon, H.; Baik, S. Knitted fabrics made from highly conductive stretchable fibers. Nano Lett. 2014, 14, 1944-1951. [CrossRef]

21. Xin, C.; Chen, L.; Li, T.; Zhang, Z.; Zhao, T.; Li, X.; Zhang, J. Highly Sensitive Flexible Pressure Sensor by the Integration of Microstructured PDMS Film With a-IGZO TFTs. IEEE Electron Device Lett. 2018, 39, 1073-1076. [CrossRef]

22. Liu, Z.; Zhao, Z.; Zeng, X.; Fu, X.; Hu, Y. Expandable microsphere-based triboelectric nanogenerators as ultrasensitive pressure sensors for respiratory and pulse monitoring. Nano Energy 2019, 59, 295-301. [CrossRef]

23. Zhuo, B.; Chen, S.; Zhao, M.; Guo, X. High Sensitivity Flexible Capacitive Pressure Sensor Using Polydimethylsiloxane Elastomer Dielectric Layer Micro-Structured by 3-D Printed Mold. IEEE J. Electron Devices Soc. 2017, 5, 219-223. [CrossRef]

24. Chen, Y.M.; He, S.M.; Huang, C.H.; Huang, C.C.; Shih, W.P.; Chu, C.L.; Kong, J.; Li, J.; Su, C.Y. Ultra-large suspended graphene as a highly elastic membrane for capacitive pressure sensors. Nanoscale 2016, 8, 3555-3564. [CrossRef] [PubMed]

25. Hou, C.; Wang, H.; Zhang, Q.; Li, Y.; Zhu, M. Highly conductive, flexible, and compressible all-graphene passive electronic skin for sensing human touch. Adv. Mater. 2014, 26, 5018-5024. [CrossRef] [PubMed]

26. Kim, K.H.; Hong, S.K.; Jang, N.S.; Ha, S.H.; Lee, H.W.; Kim, J.M. Wearable Resistive Pressure Sensor Based on Highly Flexible Carbon Composite Conductors with Irregular Surface Morphology. ACS Appl. Mater. Interfaces 2017, 9, 17499-17507. [CrossRef] [PubMed]

27. Zhao, Z.; Huang, Q.; Yan, C.; Liu, Y.; Zeng, X.; Wei, X.; Hu, Y.; Zheng, Z. Machine-washable and breathable pressure sensors based on triboelectric nanogenerators enabled by textile technologies. Nano Energy 2020, 70, 104528. [CrossRef]

28. Roh, E.; Lee, H.B.; Kim, D.I.; Lee, N.E. A Solution-Processable, Omnidirectionally Stretchable, and High-Pressure-Sensitive Piezoresistive Device. Adv. Mater. 2017, 29. [CrossRef]

29. Liang, R.; Wang, Q.-M. High sensitivity piezoelectric sensors using flexible PZT thick-film for shock tube pressure testing. Sens. Actuators A Phys. 2015, 235, 317-327. [CrossRef]

30. Ghosh, S.K.; Mandal, D. Sustainable Energy Generation from Piezoelectric Biomaterial for Noninvasive Physiological Signal Monitoring. ACS Sustain. Chem. Eng. 2017, 5, 8836-8843. [CrossRef]

31. Saraf, R.; Pu, L.; Maheshwari, V. A Light Harvesting, Self-Powered Monolith Tactile Sensor Based on Electric Field Induced Effects in MAPbI3 Perovskite. Adv. Mater. 2018, 30, 1705778. [CrossRef] [PubMed]

32. Yogeswaran, N.; Navaraj, W.T.; Gupta, S.; Liu, F.; Vinciguerra, V.; Lorenzelli, L.; Dahiya, R. Piezoelectric graphene field effect transistor pressure sensors for tactile sensing. Appl. Phys. Lett. 2018, 113, 014102. [CrossRef]

33. Yang, P.-K.; Lin, Z.-H.; Pradel, K.C.; Lin, L.; Li, X.; Wen, X.; He, J.-H.; Wang, Z.L. Paper-based origami triboelectric nanogenerators and self-powered pressure sensors. ACS Nano 2015, 9, 901-907. [CrossRef] [PubMed] 
34. Zhao, X.; Chen, B.; Wei, G.; Wu, J.M.; Han, W.; Yang, Y. Polyimide/Graphene Nanocomposite Foam-Based Wind-Driven Triboelectric Nanogenerator for Self-Powered Pressure Sensor. Adv. Mater. Technol. 2019, 4, 1800723. [CrossRef]

35. Shi, Q.; Wang, H.; Wang, T.; Lee, C. Self-powered liquid triboelectric microfluidic sensor for pressure sensing and finger motion monitoring applications. Nano Energy 2016, 30, 450-459. [CrossRef]

36. Fan, F.-R.; Tian, Z.-Q.; Lin Wang, Z. Flexible triboelectric generator. Nano Energy 2012, 1, 328-334. [CrossRef]

37. Curry, E.J.; Ke, K.; Chorsi, M.T.; Wrobel, K.S.; Miller, A.N., 3rd; Patel, A.; Kim, I.; Feng, J.; Yue, L.; Wu, Q.; et al. Biodegradable Piezoelectric Force Sensor. Proc. Natl. Acad. Sci. USA 2018, 115, 909-914. [CrossRef]

38. Chen, S.; Song, Y.; Xu, F. Flexible and Highly Sensitive Resistive Pressure Sensor Based on Carbonized Crepe Paper with Corrugated Structure. ACS Appl. Mater. Interfaces 2018, 10, 34646-34654. [CrossRef]

39. Wang, J.; Suzuki, R.; Shao, M.; Gillot, F.; Shiratori, S. Capacitive Pressure Sensor with Wide-Range, Bendable, and High Sensitivity Based on the Bionic Komochi Konbu Structure and Cu/Ni Nanofiber Network. ACS Appl. Mater. Interfaces 2019, 11, 11928-11935. [CrossRef]

40. Guo, W.; Tan, C.; Shi, K.; Li, J.; Wang, X.X.; Sun, B.; Huang, X.; Long, Y.Z.; Jiang, P. Wireless piezoelectric devices based on electrospun $\mathrm{PVDF} / \mathrm{BaTiO}_{3} \mathrm{NW}$ nanocomposite fibers for human motion monitoring. Nanoscale 2018, 10, 17751-17760. [CrossRef]

41. Yao, H.B.; Ge, J.; Wang, C.F.; Wang, X.; Hu, W.; Zheng, Z.J.; Ni, Y.; Yu, S.H. A flexible and highly pressure-sensitive graphene-polyurethane sponge based on fractured microstructure design. Adv. Mater. 2013, 25, 6692-6698. [CrossRef] [PubMed]

42. Gong, S.; Schwalb, W.; Wang, Y.; Chen, Y.; Tang, Y.; Si, J.; Shirinzadeh, B.; Cheng, W. A wearable and highly sensitive pressure sensor with ultrathin gold nanowires. Nat. Commun. 2014, 5, 3132. [CrossRef]

43. Liu, Y.; Tao, L.-Q.; Wang, D.-Y.; Zhang, T.-Y.; Yang, Y.; Ren, T.-L. Flexible, highly sensitive pressure sensor with a wide range based on graphene-silk network structure. Appl. Phys. Lett. 2017, 110, 123508. [CrossRef]

44. Ali, M.A.; Umer, R.; Khan, K.A.; Samad, Y.A.; Liao, K.; Cantwell, W. Graphene coated piezo-resistive fabrics for liquid composite molding process monitoring. Compos. Sci. Technol. 2017, 148, 106-114. [CrossRef]

45. Liu, M.; Pu, X.; Jiang, C.; Liu, T.; Huang, X.; Chen, L.; Du, C.; Sun, J.; Hu, W.; Wang, Z.L. Large-Area All-Textile Pressure Sensors for Monitoring Human Motion and Physiological Signals. Adv. Mater. 2017, 29, 1703700. [CrossRef] [PubMed]

46. Chang, H.; Kim, S.; Jin, S.; Lee, S.W.; Yang, G.T.; Lee, K.Y.; Yi, H. Ultrasensitive and Highly Stable Resistive Pressure Sensors with Biomaterial-Incorporated Interfacial Layers for Wearable Health-Monitoring and Human-Machine Interfaces. ACS Appl. Mater. Interfaces 2018, 10, 1067-1076. [CrossRef]

47. Su, B.; Gong, S.; Ma, Z.; Yap, L.W.; Cheng, W. Mimosa-inspired design of a flexible pressure sensor with touch sensitivity. Small 2015, 11, 1886-1891. [CrossRef]

48. Jeong, H.; Noh, Y.; Ko, S.H.; Lee, D. Flexible resistive pressure sensor with silver nanowire networks embedded in polymer using natural formation of air gap. Compos. Sci. Technol. 2019, 174, 50-57. [CrossRef]

49. Wang, Z.; Wang, S.; Zeng, J.; Ren, X.; Chee, A.J.; Yiu, B.Y.; Chung, W.C.; Yang, Y.; Yu, A.C.; Roberts, R.C.; et al. High Sensitivity, Wearable, Piezoresistive Pressure Sensors Based on Irregular Microhump Structures and Its Applications in Body Motion Sensing. Small 2016, 12, 3827-3836. [CrossRef]

50. Huang, Y.; Fang, D.; Wu, C.; Wang, W.; Guo, X.; Liu, P. A flexible touch-pressure sensor array with wireless transmission system for robotic skin. Rev. Sci. Instrum. 2016, 87, 065007. [CrossRef]

51. Pan, J.; Liu, S.; Yang, Y.; Lu, J. A Highly Sensitive Resistive Pressure Sensor Based on a Carbon Nanotube-Liquid Crystal-PDMS Composite. Nanomaterials (Basel) 2018, 8, 413. [CrossRef] [PubMed]

52. Tung, T.T.; Robert, C.; Castro, M.; Feller, J.F.; Kim, T.Y.; Suh, K.S. Enhancing the sensitivity of graphene/polyurethane nanocomposite flexible piezo-resistive pressure sensors with magnetite nano-spacers. Carbon 2016, 108, 450-460. [CrossRef]

53. Yap, L.W.; Gong, S.; Tang, Y.; Zhu, Y.; Cheng, W. Soft piezoresistive pressure sensing matrix from copper nanowires composite aerogel. Sci. Bull. 2016, 61, 1624-1630. [CrossRef]

54. Lee, S.; Reuveny, A.; Reeder, J.; Lee, S.; Jin, H.; Liu, Q.; Yokota, T.; Sekitani, T.; Isoyama, T.; Abe, Y.; et al. A transparent bending-insensitive pressure sensor. Nat. Nanotechnol. 2016, 11, 472-478. [CrossRef]

55. Lee, S.; Shin, S.; Lee, S.; Seo, J.; Lee, J.; Son, S.; Cho, H.J.; Algadi, H.; Al-Sayari, S.; Kim, D.E.; et al. Ag Nanowire Reinforced Highly Stretchable Conductive Fibers for Wearable Electronics. Adv. Funct. Mater. 2015, 25, 3114-3121. [CrossRef] 
56. Lee, G.-Y.; Lee, H.-T.; Ryu, W.; Ahn, S.-H.; Yang, J. Resistive pressure sensor based on cylindrical micro structures in periodically ordered electrospun elastic fibers. Smart Mater. Struct. 2018, 27, 11LT01. [CrossRef]

57. Woo, S.-J.; Kong, J.-H.; Kim, D.-G.; Kim, J.-M. A thin all-elastomeric capacitive pressure sensor array based on micro-contact printed elastic conductors. J. Mater. Chem. C 2014, 2, 4415-4422. [CrossRef]

58. Lei, K.F.; Lee, K.-F.; Lee, M.-Y. Development of a flexible PDMS capacitive pressure sensor for plantar pressure measurement. Microelectron. Eng. 2012, 99, 1-5. [CrossRef]

59. Shi, H.; Al-Rubaiai, M.; Holbrook, C.M.; Miao, J.; Pinto, T.; Wang, C.; Tan, X. Screen-Printed Soft Capacitive Sensors for Spatial Mapping of Both Positive and Negative Pressures. Adv. Funct. Mater. 2019, $29,1809116$. [CrossRef]

60. Lipomi, D.J.; Vosgueritchian, M.; Tee, B.C.; Hellstrom, S.L.; Lee, J.A.; Fox, C.H.; Bao, Z. Skin-like pressure and strain sensors based on transparent elastic films of carbon nanotubes. Nat. Nanotechnol. 2011, 6, 788-792. [CrossRef]

61. Yao, S.; Zhu, Y. Wearable multifunctional sensors using printed stretchable conductors made of silver nanowires. Nanoscale 2014, 6, 2345-2352. [CrossRef] [PubMed]

62. Mitrakos, V.; Macintyre, L.; Denison, F.; Hands, P.; Desmulliez, M. Design, Manufacture and Testing of Capacitive Pressure Sensors for Low-Pressure Measurement Ranges. Micromachines 2017, 8, 41. [CrossRef]

63. Luo, Y.; Shao, J.; Chen, S.; Chen, X.; Tian, H.; Li, X.; Wang, L.; Wang, D.; Lu, B. Flexible Capacitive Pressure Sensor Enhanced by Tilted Micropillar Arrays. ACS Appl. Mater. Interfaces 2019, 11, 17796-17803. [CrossRef] [PubMed]

64. Shuai, X.; Zhu, P.; Zeng, W.; Hu, Y.; Liang, X.; Zhang, Y.; Sun, R.; Wong, C.P. Highly Sensitive Flexible Pressure Sensor Based on Silver Nanowires-Embedded Polydimethylsiloxane Electrode with Microarray Structure. ACS Appl. Mater. Interfaces 2017, 9, 26314-26324. [CrossRef]

65. Ruth, S.R.A.; Beker, L.; Tran, H.; Feig, V.R.; Matsuhisa, N.; Bao, Z. Rational Design of Capacitive Pressure Sensors Based on Pyramidal Microstructures for Specialized Monitoring of Biosignals. Adv. Funct. Mater. 2019, 30, 1903100. [CrossRef]

66. Tee, B.C.K.; Chortos, A.; Dunn, R.R.; Schwartz, G.; Eason, E.; Bao, Z. Tunable Flexible Pressure Sensors using Microstructured Elastomer Geometries for Intuitive Electronics. Adv. Funct. Mater. 2014, 24, 5427-5434. [CrossRef]

67. Yoon, J.I.; Choi, K.S.; Chang, S.P. A novel means of fabricating microporous structures for the dielectric layers of capacitive pressure sensor. Microelectron. Eng. 2017, 179, 60-66. [CrossRef]

68. Kwon, D.; Lee, T.I.; Shim, J.; Ryu, S.; Kim, M.S.; Kim, S.; Kim, T.S.; Park, I. Highly Sensitive, Flexible, and Wearable Pressure Sensor Based on a Giant Piezocapacitive Effect of Three-Dimensional Microporous Elastomeric Dielectric Layer. ACS Appl. Mater. Interfaces 2016, 8, 16922-16931. [CrossRef]

69. Park, S.W.; Das, P.S.; Chhetry, A.; Park, J.Y. A Flexible Capacitive Pressure Sensor for Wearable Respiration Monitoring System. IEEE Sens. J. 2017, 17, 6558-6564. [CrossRef]

70. Kang, S.; Lee, J.; Lee, S.; Kim, S.; Kim, J.-K.; Algadi, H.; Al-Sayari, S.; Kim, D.-E.; Kim, D.; Lee, T. Highly Sensitive Pressure Sensor Based on Bioinspired Porous Structure for Real-Time Tactile Sensing. Adv. Electron. Mater. 2016, 2, 1600356. [CrossRef]

71. Lee, B.-Y.; Kim, J.; Kim, H.; Kim, C.; Lee, S.-D. Low-cost flexible pressure sensor based on dielectric elastomer film with micro-pores. Sens. Actuators A Phys. 2016, 240, 103-109. [CrossRef]

72. Kim, Y.; Jang, S.; Oh, J.H. Fabrication of highly sensitive capacitive pressure sensors with porous PDMS dielectric layer via microwave treatment. Microelectron. Eng. 2019, 215, 111002. [CrossRef]

73. Yang, J.C.; Kim, J.O.; Oh, J.; Kwon, S.Y.; Sim, J.Y.; Kim, D.W.; Choi, H.B.; Park, S. Microstructured Porous Pyramid-Based Ultrahigh Sensitive Pressure Sensor Insensitive to Strain and Temperature. ACS Appl. Mater. Interfaces 2019, 11, 19472-19480. [CrossRef] [PubMed]

74. Chhetry, A.; Yoon, H.; Park, J.Y. A flexible and highly sensitive capacitive pressure sensor based on conductive fibers with a microporous dielectric for wearable electronics. J. Mater. Chem. C 2017, 5, 10068-10076. [CrossRef]

75. Wei, P.; Guo, X.; Qiu, X.; Yu, D. Flexible capacitive pressure sensor with sensitivity and linear measuring range enhanced based on porous composite of carbon conductive paste and polydimethylsiloxane. Nanotechnolgy 2019, 30, 455501. [CrossRef]

76. Choi, J.; Kwon, D.; Kim, K.; Park, J.; Orbe, D.D.; Gu, J.; Ahn, J.; Cho, I.; Jeong, Y.; Oh, Y.; et al. Synergetic Effect of Porous Elastomer and Percolation of Carbon Nanotube Filler toward High Performance Capacitive Pressure Sensors. ACS Appl. Mater. Interfaces 2020, 12, 1698-1706. [CrossRef] 
77. Fuh, Y.K.; Wang, B.S.; Tsai, C.Y. Self-Powered Pressure Sensor with fully encapsulated 3D printed wavy substrate and highly-aligned piezoelectric fibers array. Sci. Rep. 2017, 7, 6759. [CrossRef]

78. Kim, H.; Torres, F.; Villagran, D.; Stewart, C.; Lin, Y.; Tseng, T.-L.B. 3D Printing of $\mathrm{BaTiO}_{3} / \mathrm{PVDF}_{\text {Composites }}$ with Electric In Situ Poling for Pressure Sensor Applications. Macromol. Mater. Eng. 2017, 302, 1700229. [CrossRef]

79. Chen, X.; Li, X.; Shao, J.; An, N.; Tian, H.; Wang, C.; Han, T.; Wang, L.; Lu, B. High-Performance Piezoelectric

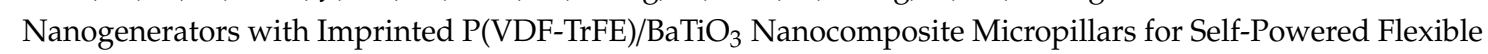
Sensors. Small 2017, 13, 1604245. [CrossRef]

80. Alluri, N.R.; Selvarajan, S.; Chandrasekhar, A.; Saravanakumar, B.; Jeong, J.H.; Kim, S.-J. Piezoelectric $\mathrm{BaTiO}_{3} /$ alginate spherical composite beads for energy harvesting and self-powered wearable flexion sensor. Compos. Sci. Technol. 2017, 142, 65-78. [CrossRef]

81. Chun, J.; Lee, K.Y.; Kang, C.-Y.; Kim, M.W.; Kim, S.-W.; Baik, J.M. Embossed Hollow Hemisphere-Based Piezoelectric Nanogenerator and Highly Responsive Pressure Sensor. Adv. Funct. Mater. 2014, 24, 2038-2043. [CrossRef]

82. Chen, Z.; Wang, Z.; Li, X.; Lin, Y.; Luo, N.; Long, M.; Zhao, N.; Xu, J.B. Flexible Piezoelectric-Induced Pressure Sensors for Static Measurements Based on Nanowires/Graphene Heterostructures. ACS Nano 2017, 11, 4507-4513. [CrossRef] [PubMed]

83. Jeong, Y.; Sim, M.; Shin, J.H.; Choi, J.-W.; Sohn, J.I.; Cha, S.N.; Choi, H.; Moon, C.; Jang, J.E. Psychological tactile sensor structure based on piezoelectric nanowire cell arrays. RSC Adv. 2015, 5, 40363-40368. [CrossRef]

84. Choi, W.; Lee, J.; Kyoung Yoo, Y.; Kang, S.; Kim, J.; Hoon Lee, J. Enhanced sensitivity of piezoelectric pressure sensor with microstructured polydimethylsiloxane layer. Appl. Phys. Lett. 2014, 104, 123701. [CrossRef]

85. Lee, J.-H.; Yoon, H.-J.; Kim, T.Y.; Gupta, M.K.; Lee, J.H.; Seung, W.; Ryu, H.; Kim, S.-W. Micropatterned P(VDF-TrFE) Film-Based Piezoelectric Nanogenerators for Highly Sensitive Self-Powered Pressure Sensors. Adv. Funct. Mater. 2015, 25, 3203-3209. [CrossRef]

86. Tian, G.; Deng, W.; Gao, Y.; Xiong, D.; Yan, C.; He, X.; Yang, T.; Jin, L.; Chu, X.; Zhang, H.; et al. Rich lamellar crystal baklava-structured PZT/PVDF piezoelectric sensor toward individual table tennis training. Nano Energy 2019, 59, 574-581. [CrossRef]

87. Chen, X.; Shao, J.; An, N.; Li, X.; Tian, H.; Xu, C.; Ding, Y. Self-powered flexible pressure sensors with vertically well-aligned piezoelectric nanowire arrays for monitoring vital signs. J. Mater. Chem. C 2015, 3, 11806-11814. [CrossRef]

88. Parida, K.; Bhavanasi, V.; Kumar, V.; Bendi, R.; Lee, P.S. Self-powered pressure sensor for ultra-wide range pressure detection. Nano Res. 2017, 10, 3557-3570. [CrossRef]

89. Ai, Y.; Lou, Z.; Chen, S.; Chen, D.; Wang, Z.M.; Jiang, K.; Shen, G. All rGO-on-PVDF-nanofibers based self-powered electronic skins. Nano Energy 2017, 35, 121-127. [CrossRef]

90. Park, S.H.; Lee, H.B.; Yeon, S.M.; Park, J.; Lee, N.K. Flexible and Stretchable Piezoelectric Sensor with Thickness-Tunable Configuration of Electrospun Nanofiber Mat and Elastomeric Substrates. ACS Appl. Mater. Interfaces 2016, 8, 24773-24781. [CrossRef]

91. Gao, Q.; Meguro, H.; Okamoto, S.; Kimura, M. Flexible tactile sensor using the reversible deformation of poly(3-hexylthiophene) nanofiber assemblies. Langmuir 2012, 28, 17593-17596. [CrossRef] [PubMed]

92. Xin, Y.; Qi, X.; Tian, H.; Guo, C.; Li, X.; Lin, J.; Wang, C. Full-fiber piezoelectric sensor by straight PVDF/nanoclay nanofibers. Mater. Lett. 2016, 164, 136-139. [CrossRef]

93. Zhao, G.; Zhang, X.; Cui, X.; Wang, S.; Liu, Z.; Deng, L.; Qi, A.; Qiao, X.; Li, L.; Pan, C.; et al. Piezoelectric Polyacrylonitrile Nanofiber Film-Based Dual-Function Self-Powered Flexible Sensor. ACS Appl. Mater. Interfaces 2018, 10, 15855-15863. [CrossRef] [PubMed]

94. Ahmed, A.; Jia, Y.; Huang, Y.; Khoso, N.A.; Deb, H.; Fan, Q.; Shao, J. Preparation of PVDF-TrFE based electrospun nanofibers decorated with PEDOT-CNT/rGO composites for piezo-electric pressure sensor. J. Mater. Sci. Mater. Electron. 2019, 30, 14007-14021. [CrossRef]

95. Spanu, A.; Pinna, L.; Viola, F.; Seminara, L.; Valle, M.; Bonfiglio, A.; Cosseddu, P. A high-sensitivity tactile sensor based on piezoelectric polymer PVDF coupled to an ultra-low voltage organic transistor. Org. Electron. 2016, 36, 57-60. [CrossRef]

96. Zhang, Q.; Leonardi, F.; Pfattner, R.; Mas-Torrent, M. A Solid-State Aqueous Electrolyte-Gated Field-Effect Transistor as a Low-Voltage Operation Pressure-Sensitive Platform. Adv. Mater. Interfaces 2019, 6, 1900719. [CrossRef] 
97. Schwartz, G.; Tee, B.C.; Mei, J.; Appleton, A.L.; Kim, D.H.; Wang, H.; Bao, Z. Flexible polymer transistors with high pressure sensitivity for application in electronic skin and health monitoring. Nat. Commun. 2013, 4, 1859. [CrossRef]

98. Wang, Z.; Guo, S.; Li, H.; Wang, B.; Sun, Y.; Xu, Z.; Chen, X.; Wu, K.; Zhang, X.; Xing, F.; et al. The Semiconductor/Conductor Interface Piezoresistive Effect in an Organic Transistor for Highly Sensitive Pressure Sensors. Adv. Mater. 2019, 31, 1805630. [CrossRef]

99. Kyaw, A.K.K.; Loh, H.H.C.; Yan, F.; Xu, J. A polymer transistor array with a pressure-sensitive elastomer for electronic skin. J. Mater. Chem. C 2017, 5, 12039-12043. [CrossRef]

100. Joo, Y.; Yoon, J.; Ha, J.; Kim, T.; Lee, S.; Lee, B.; Pang, C.; Hong, Y. Highly Sensitive and Bendable Capacitive Pressure Sensor and Its Application to $1 \mathrm{~V}$ Operation Pressure-Sensitive Transistor. Adv. Electron. Mater. 2017, 3, 1600455. [CrossRef]

101. Lee, D.; Chung, J.; Yong, H.; Lee, S.; Shin, D. A Deformable Foam-Layered Triboelectric Tactile Sensor with Adjustable Dynamic Range. Int. J. Precis. Eng. Manuf.-Green Technol. 2019, 6, 43-51. [CrossRef]

102. Vivekananthan, V.; Chandrasekhar, A.; Alluri, N.R.; Purusothaman, Y.; Kim, S.-J. A highly reliable, impervious and sustainable triboelectric nanogenerator as a zero-power consuming active pressure sensor. Nanoscale Adv. 2020, 2, 746-754. [CrossRef]

103. Meng, B.; Tang, W.; Too, Z.-h.; Zhang, X.; Han, M.; Liu, W.; Zhang, H. A transparent single-friction-surface triboelectric generator and self-powered touch sensor. Energy Environ. Sci. 2013, 6, 3235-3240. [CrossRef]

104. Fan, F.R.; Lin, L.; Zhu, G.; Wu, W.; Zhang, R.; Wang, Z.L. Transparent triboelectric nanogenerators and self-powered pressure sensors based on micropatterned plastic films. Nano Lett. 2012, 12, 3109-3114. [CrossRef] [PubMed]

105. Rasel, M.S.; Maharjan, P.; Salauddin, M.; Rahman, M.T.; Cho, H.O.; Kim, J.W.; Park, J.Y. An impedance tunable and highly efficient triboelectric nanogenerator for large-scale, ultra-sensitive pressure sensing applications. Nano Energy 2018, 49, 603-613. [CrossRef]

106. Yao, G.; Xu, L.; Cheng, X.; Li, Y.; Huang, X.; Guo, W.; Liu, S.; Wang, Z.L.; Wu, H. Bioinspired Triboelectric Nanogenerators as Self-Powered Electronic Skin for Robotic Tactile Sensing. Adv. Funct. Mater. 2019, 30, 1907312. [CrossRef]

107. Chen, F.; Wu, Y.; Ding, Z.; Xia, X.; Li, S.; Zheng, H.; Diao, C.; Yue, G.; Zi, Y. A novel triboelectric nanogenerator based on electrospun polyvinylidene fluoride nanofibers for effective acoustic energy harvesting and self-powered multifunctional sensing. Nano Energy 2019, 56, 241-251. [CrossRef]

108. Lin, M.-F.; Xiong, J.; Wang, J.; Parida, K.; Lee, P.S. Core-shell nanofiber mats for tactile pressure sensor and nanogenerator applications. Nano Energy 2018, 44, 248-255. [CrossRef]

109. Garain, S.; Jana, S.; Sinha, T.K.; Mandal, D. Design of In Situ Poled Ce ${ }^{3+}$-Doped Electrospun PVDF/Graphene Composite Nanofibers for Fabrication of Nanopressure Sensor and Ultrasensitive Acoustic Nanogenerator. ACS Appl. Mater. Interfaces 2016, 8, 4532-4540. [CrossRef]

110. Mi, H.-Y.; Jing, X.; Zheng, Q.; Fang, L.; Huang, H.-X.; Turng, L.-S.; Gong, S. High-performance flexible triboelectric nanogenerator based on porous aerogels and electrospun nanofibers for energy harvesting and sensitive self-powered sensing. Nano Energy 2018, 48, 327-336. [CrossRef]

111. Kim, Y.; Jang, S.; Kang, B.J.; Oh, J.H. Fabrication of highly sensitive capacitive pressure sensors with electrospun polymer nanofibers. Appl. Phys. Lett. 2017, 111, 073502. [CrossRef]

112. Sharma, S.; Chhetry, A.; Sharifuzzaman, M.; Yoon, H.; Park, J.Y. Wearable Capacitive Pressure Sensor Based on MXene Composite Nanofibrous Scaffolds for Reliable Human Physiological Signal Acquisition. ACS Appl. Mater. Interfaces 2020, 12, 22212-22224. [CrossRef] [PubMed]

113. Garcia, C.; Trendafilova, I.; Guzman de Villoria, R.; Sanchez del Rio, J. Self-powered pressure sensor based on the triboelectric effect and its analysis using dynamic mechanical analysis. Nano Energy 2018, 50, 401-409. [CrossRef]

114. Xiong, Y.; Shen, Y.; Tian, L.; Hu, Y.; Zhu, P.; Sun, R.; Wong, C.-P. A flexible, ultra-highly sensitive and stable capacitive pressure sensor with convex microarrays for motion and health monitoring. Nano Energy 2020, 70, 104436. [CrossRef]

115. Jang, S.; Oh, J.H. Rapid Fabrication of Microporous $\mathrm{BaTiO}_{3} / \mathrm{PDMS}$ Nanocomposites for Triboelectric Nanogenerators through One-step Microwave Irradiation. Sci. Rep. 2018, 8, 14287. [CrossRef]

116. Pang, C.; Lee, G.Y.; Kim, T.I.; Kim, S.M.; Kim, H.N.; Ahn, S.H.; Suh, K.Y. A flexible and highly sensitive strain-gauge sensor using reversible interlocking of nanofibres. Nat. Mater. 2012, 11, 795-801. [CrossRef] 
117. Choong, C.L.; Shim, M.B.; Lee, B.S.; Jeon, S.; Ko, D.S.; Kang, T.H.; Bae, J.; Lee, S.H.; Byun, K.E.; Im, J.; et al. Highly stretchable resistive pressure sensors using a conductive elastomeric composite on a micropyramid array. Adv. Mater. 2014, 26, 3451-3458. [CrossRef]

118. Zhu, B.; Niu, Z.; Wang, H.; Leow, W.R.; Wang, H.; Li, Y.; Zheng, L.; Wei, J.; Huo, F.; Chen, X. Microstructured graphene arrays for highly sensitive flexible tactile sensors. Small 2014, 10, 3625-3631. [CrossRef]

119. Wang, X.; Gu, Y.; Xiong, Z.; Cui, Z.; Zhang, T. Silk-molded flexible, ultrasensitive, and highly stable electronic skin for monitoring human physiological signals. Adv. Mater. 2014, 26, 1336-1342. [CrossRef]

120. Liang, G.; Wang, Y.; Mei, D.; Xi, K.; Chen, Z. An analytical model for studying the structural effects and optimization of a capacitive tactile sensor array. J. Micromech. Microeng. 2016, 26, 045007. [CrossRef]

121. Baek, S.; Jang, H.; Kim, S.Y.; Jeong, H.; Han, S.; Jang, Y.; Kim, D.H.; Lee, H.S. Flexible piezocapacitive sensors based on wrinkled microstructures: Toward low-cost fabrication of pressure sensors over large areas. RSC Adv. 2017, 7, 39420-39426. [CrossRef]

122. Kim, H.; Torres, F.; Wu, Y.; Villagran, D.; Lin, Y.; Tseng, T.-L. Integrated 3D printing and corona poling process of PVDF piezoelectric films for pressure sensor application. Smart Mater. Struct. 2017, 26, 085027. [CrossRef]

123. Leigh, S.J.; Bradley, R.J.; Purssell, C.P.; Billson, D.R.; Hutchins, D.A. A simple, low-cost conductive composite material for 3D printing of electronic sensors. PLoS ONE 2012, 7, 49365. [CrossRef] [PubMed]

124. Gräbner, D.; Tintelott, M.; Dumstorff, G.; Lang, W. Low-Cost Thin and Flexible Screen-Printed Pressure Sensor. Proceedings 2017, 1, 616. [CrossRef]

125. Peng, Y.; Xiao, S.; Yang, J.; Lin, J.; Yuan, W.; Gu, W.; Wu, X.; Cui, Z. The elastic microstructures of inkjet printed polydimethylsiloxane as the patterned dielectric layer for pressure sensors. Appl. Phys. Lett. 2017, 110, 261904. [CrossRef]

126. Yang, X.; Wang, Y.; Sun, H.; Qing, X. A flexible ionic liquid-polyurethane sponge capacitive pressure sensor. Sens. Actuators A Phys. 2019, 285, 67-72. [CrossRef]

127. Hu, W.; Niu, X.; Zhao, R.; Pei, Q. Elastomeric transparent capacitive sensors based on an interpenetrating composite of silver nanowires and polyurethane. Appl. Phys. Lett. 2013, 102, 083303. [CrossRef]

128. Wan, S.; Bi, H.; Zhou, Y.; Xie, X.; Su, S.; Yin, K.; Sun, L. Graphene oxide as high-performance dielectric materials for capacitive pressure sensors. Carbon 2017, 114, 209-216. [CrossRef]

129. Huang, C.B.; Witomska, S.; Aliprandi, A.; Stoeckel, M.A.; Bonini, M.; Ciesielski, A.; Samori, P. Molecule-Graphene Hybrid Materials with Tunable Mechanoresponse: Highly Sensitive Pressure Sensors for Health Monitoring. Adv. Mater. 2019, 31, 1804600. [CrossRef]

130. Wang, J.; Jiu, J.; Nogi, M.; Sugahara, T.; Nagao, S.; Koga, H.; He, P.; Suganuma, K. A highly sensitive and flexible pressure sensor with electrodes and elastomeric interlayer containing silver nanowires. Nanoscale 2015, 7, 2926-2932. [CrossRef]

131. Dobrzynska, J.A.; Gijs, M.A.M. Flexible polyimide-based force sensor. Sens. Actuators A Phys. 2012, 173, 127-135. [CrossRef]

132. Li, W.; Xiong, L.; Pu, Y.; Quan, Y.; Li, S. High-Performance Paper-Based Capacitive Flexible Pressure Sensor and Its Application in Human-Related Measurement. Nanoscale Res. Lett. 2019, 14, 183. [CrossRef]

133. Dobrzynska, J.A.; Gijs, M.A.M. Polymer-based flexible capacitive sensor for three-axial force measurements. J. Micromech. Microeng. 2013, 23, 015009. [CrossRef]

134. Joo, Y.; Byun, J.; Seong, N.; Ha, J.; Kim, H.; Kim, S.; Kim, T.; Im, H.; Kim, D.; Hong, Y. Silver nanowire-embedded PDMS with a multiscale structure for a highly sensitive and robust flexible pressure sensor. Nanoscale 2015, 7, 6208-6215. [CrossRef]

135. Zhou, Q.; Ji, B.; Wei, Y.; Hu, B.; Gao, Y.; Xu, Q.; Zhou, J.; Zhou, B. A bio-inspired cilia array as the dielectric layer for flexible capacitive pressure sensors with high sensitivity and a broad detection range. J. Mater. Chem. A 2019, 7, 27334-27346. [CrossRef]

136. Mannsfeld, S.C.; Tee, B.C.; Stoltenberg, R.M.; Chen, C.V.; Barman, S.; Muir, B.V.; Sokolov, A.N.; Reese, C.; Bao, Z. Highly sensitive flexible pressure sensors with microstructured rubber dielectric layers. Nat. Mater. 2010, 9, 859-864. [CrossRef] [PubMed]

137. Park, D.Y.; Joe, D.J.; Kim, D.H.; Park, H.; Han, J.H.; Jeong, C.K.; Park, H.; Park, J.G.; Joung, B.; Lee, K.J. Self-Powered Real-Time Arterial Pulse Monitoring Using Ultrathin Epidermal Piezoelectric Sensors. Adv. Mater. 2017, 29, 1702308. [CrossRef] [PubMed]

138. Núñez, C.G.; Navaraj, W.T.; Polat, E.O.; Dahiya, R. Energy-Autonomous, Flexible, and Transparent Tactile Skin. Adv. Funct. Mater. 2017, 27, 1606287. [CrossRef] 
139. Zhang, Y.; Lin, Z.; Huang, X.; You, X.; Ye, J.; Wu, H. Highly sensitive capacitive pressure sensor with elastic metallized sponge. Smart Mater. Struct. 2019, 28, 105023. [CrossRef]

140. Ramalingame, R.; Lakshmanan, A.; Müller, F.; Thomas, U.; Kanoun, O. Highly sensitive capacitive pressure sensors for robotic applications based on carbon nanotubes and PDMS polymer nanocomposite. J. Sens. Sens. Syst. 2019, 8, 87-94. [CrossRef]

141. Lee, J.; Kwon, H.; Seo, J.; Shin, S.; Koo, J.H.; Pang, C.; Son, S.; Kim, J.H.; Jang, Y.H.; Kim, D.E.; et al. Conductive fiber-based ultrasensitive textile pressure sensor for wearable electronics. Adv. Mater. 2015, 27, 2433-2439. [CrossRef] [PubMed]

142. Hwang, B.-U.; Zabeeb, A.; Trung, T.Q.; Wen, L.; Lee, J.D.; Choi, Y.-I.; Lee, H.-B.; Kim, J.H.; Han, J.G.; Lee, N.-E. A transparent stretchable sensor for distinguishable detection of touch and pressure by capacitive and piezoresistive signal transduction. NPG Asia Mater. 2019, 11, 23. [CrossRef]

143. Pan, L.; Chortos, A.; Yu, G.; Wang, Y.; Isaacson, S.; Allen, R.; Shi, Y.; Dauskardt, R.; Bao, Z. An ultra-sensitive resistive pressure sensor based on hollow-sphere microstructure induced elasticity in conducting polymer film. Nat. Commun. 2014, 5, 3002. [CrossRef] [PubMed]

144. Jung, S.; Kim, J.H.; Kim, J.; Choi, S.; Lee, J.; Park, I.; Hyeon, T.; Kim, D.H. Reverse-micelle-induced porous pressure-sensitive rubber for wearable human-machine interfaces. Adv. Mater. 2014, 26, 4825-4830. [CrossRef]

145. Lai, Y.C.; Deng, J.; Liu, R.; Hsiao, Y.C.; Zhang, S.L.; Peng, W.; Wu, H.M.; Wang, X.; Wang, Z.L. Actively Perceiving and Responsive Soft Robots Enabled by Self-Powered, Highly Extensible, and Highly Sensitive Triboelectric Proximity- and Pressure-Sensing Skins. Adv. Mater. 2018, 30, 1801114. [CrossRef]

146. Nie, B.; Li, R.; Cao, J.; Brandt, J.D.; Pan, T. Flexible transparent iontronic film for interfacial capacitive pressure sensing. Adv. Mater. 2015, 27, 6055-6062. [CrossRef]

147. Kim, D.; Kim, D.; Lee, H.; Jeong, Y.R.; Lee, S.J.; Yang, G.; Kim, H.; Lee, G.; Jeon, S.; Zi, G.; et al. Body-Attachable and Stretchable Multisensors Integrated with Wirelessly Rechargeable Energy Storage Devices. Adv. Mater. 2016, 28, 748-756. [CrossRef]

148. Bae, G.Y.; Pak, S.W.; Kim, D.; Lee, G.; Kim do, H.; Chung, Y.; Cho, K. Linearly and Highly Pressure-Sensitive Electronic Skin Based on a Bioinspired Hierarchical Structural Array. Adv. Mater. 2016, 28, 5300-5306. [CrossRef]

149. Hamdani, S.T.; Fernando, A. The application of a piezo-resistive cardiorespiratory sensor system in an automobile safety belt. Sensors (Basel) 2015, 15, 7742-7753. [CrossRef]

150. Yeo, S.Y.; Park, S.; Yi, Y.J.; Kim, D.H.; Lim, J.A. Highly Sensitive Flexible Pressure Sensors Based on Printed Organic Transistors with Centro-Apically Self-Organized Organic Semiconductor Microstructures. ACS Appl. Mater. Interfaces 2017, 9, 42996-43003. [CrossRef]

151. Zhao, G.; Zhang, Y.; Shi, N.; Liu, Z.; Zhang, X.; Wu, M.; Pan, C.; Liu, H.; Li, L.; Wang, Z.L. Transparent and stretchable triboelectric nanogenerator for self-powered tactile sensing. Nano Energy 2019, 59, 302-310. [CrossRef]

152. He, Z.; Chen, W.; Liang, B.; Liu, C.; Yang, L.; Lu, D.; Mo, Z.; Zhu, H.; Tang, Z.; Gui, X. Capacitive Pressure Sensor with High Sensitivity and Fast Response to Dynamic Interaction Based on Graphene and Porous Nylon Networks. ACS Appl. Mater. Interfaces 2018, 10, 12816-12823. [CrossRef] [PubMed]

153. Kim, S.Y.; Park, S.; Park, H.W.; Park, D.H.; Jeong, Y.; Kim, D.H. Highly Sensitive and Multimodal All-Carbon Skin Sensors Capable of Simultaneously Detecting Tactile and Biological Stimuli. Adv. Mater. 2015, 27, 4178-4185. [CrossRef] [PubMed]

154. Bae, G.Y.; Han, J.T.; Lee, G.; Lee, S.; Kim, S.W.; Park, S.; Kwon, J.; Jung, S.; Cho, K. Pressure/Temperature Sensing Bimodal Electronic Skin with Stimulus Discriminability and Linear Sensitivity. Adv. Mater. 2018, 30, 1803388. [CrossRef]

155. Tian, H.; Shu, Y.; Wang, X.F.; Mohammad, M.A.; Bie, Z.; Xie, Q.Y.; Li, C.; Mi, W.T.; Yang, Y.; Ren, T.L. A graphene-based resistive pressure sensor with record-high sensitivity in a wide pressure range. Sci. Rep. 2015, 5, 8603. [CrossRef]

156. Liu, S.-Y.; Lian, L.; Pan, J.; Lu, J.-G.; Shieh, H.-P.D. Highly Sensitive and Optically Transparent Resistive Pressure Sensors Based on a Graphene/Polyaniline-Embedded PVB Film. IEEE Trans. Electron Devices 2018, 65, 1939-1945. [CrossRef]

157. Casula, G.; Cosseddu, P.; Bonfiglio, A. Integration of an Organic Resistive Memory with a Pressure-Sensitive Element on a Fully Flexible Substrate. Adv. Electron. Mater. 2015, 1, 1500234. [CrossRef] 
158. Vishniakou, S.; Chen, R.; Ro, Y.G.; Brennan, C.J.; Levy, C.; Yu, E.T.; Dayeh, S.A. Improved Performance of Zinc Oxide Thin Film Transistor Pressure Sensors and a Demonstration of a Commercial Chip Compatibility with the New Force Sensing Technology. Adv. Mater. Technol. 2018, 3, 1700279. [CrossRef]

159. Yin, M.-J.; Yin, Z.; Zhang, Y.; Zheng, Q.; Zhang, A.P. Micropatterned elastic ionic polyacrylamide hydrogel for low-voltage capacitive and organic thin-film transistor pressure sensors. Nano Energy 2019, 58, 96-104. [CrossRef]

160. Takei, K.; Takahashi, T.; Ho, J.C.; Ko, H.; Gillies, A.G.; Leu, P.W.; Fearing, R.S.; Javey, A. Nanowire active-matrix circuitry for low-voltage macroscale artificial skin. Nat Mater. 2010, 9, 821-826. [CrossRef]

161. Sun, Q.; Kim, D.H.; Park, S.S.; Lee, N.Y.; Zhang, Y.; Lee, J.H.; Cho, K.; Cho, J.H. Transparent, low-power pressure sensor matrix based on coplanar-gate graphene transistors. Adv. Mater. 2014, 26, 4735-4740. [CrossRef]

162. Wang, C.; Hwang, D.; Yu, Z.; Takei, K.; Park, J.; Chen, T.; Ma, B.; Javey, A. User-interactive electronic skin for instantaneous pressure visualization. Nat. Mater. 2013, 12, 899-904. [CrossRef] [PubMed]

163. Dong, K.; Wu, Z.; Deng, J.; Wang, A.C.; Zou, H.; Chen, C.; Hu, D.; Gu, B.; Sun, B.; Wang, Z.L. A Stretchable Yarn Embedded Triboelectric Nanogenerator as Electronic Skin for Biomechanical Energy Harvesting and Multifunctional Pressure Sensing. Adv. Mater. 2018, 30, 1804944. [CrossRef] [PubMed]

164. Lee, K.Y.; Yoon, H.-J.; Jiang, T.; Wen, X.; Seung, W.; Kim, S.-W.; Wang, Z.L. Fully Packaged Self-Powered Triboelectric Pressure Sensor Using Hemispheres-Array. Adv. Energy Mater. 2016, 6, 1502566. [CrossRef]

165. Yang, Y.; Zhang, H.; Lin, Z.-H.; Zhou, Y.S.; Jing, Q.; Su, Y.; Yang, J.; Chen, J.; Hu, C.; Wang, Z.L. Human skin based triboelectric nanogenerators for harvesting biomechanical energy and as self-powered active tactile sensor system. ACS Nano 2013, 7, 9213-9222. [CrossRef]

166. Dhakar, L.; Gudla, S.; Shan, X.; Wang, Z.; Tay, F.E.; Heng, C.H.; Lee, C. Large Scale Triboelectric Nanogenerator and Self-Powered Pressure Sensor Array Using Low Cost Roll-to-Roll UV Embossing. Sci. Rep. 2016, 6, 22253. [CrossRef] [PubMed]

167. Wang, X.; Zhang, H.; Dong, L.; Han, X.; Du, W.; Zhai, J.; Pan, C.; Wang, Z.L. Self-Powered High-Resolution and Pressure-Sensitive Triboelectric Sensor Matrix for Real-Time Tactile Mapping. Adv. Mater. 2016, 28, 2896-2903. [CrossRef]

168. Pu, X.; Liu, M.; Chen, X.; Sun, J.; Du, C.; Zhang, Y.; Zhai, J.; Hu, W.; Wang, Z.L. Ultrastretchable, transparent triboelectric nanogenerator as electronic skin for biomechanical energy harvesting and tactile sensing. Sci. Adv. 2017, 3, e1700015. [CrossRef] [PubMed]

169. Kim, D.; Yoon, Y.; Kauh, S.K.; Lee, J. Towards Sub-Microscale Liquid Metal Patterns: Cascade Phase Change Mediated Pick-n-Place Transfer of Liquid Metals Printed and Stretched over a Flexible Substrate. Adv. Funct. Mater. 2018, 28, 1800380. [CrossRef]

(C) 2020 by the authors. Licensee MDPI, Basel, Switzerland. This article is an open access article distributed under the terms and conditions of the Creative Commons Attribution (CC BY) license (http://creativecommons.org/licenses/by/4.0/). 